\title{
Assimilation of Doppler Radar Data and Its Impact on Prediction of a Heavy Meiyu Frontal Rainfall Event
}

\author{
Hongli Li $\left(\mathbb{D},{ }^{1,2,3}\right.$ Xiangde $\mathrm{Xu}^{3}{ }^{3}$ Yang $\mathrm{Hu},{ }^{1}$ Yanjiao Xiao, ${ }^{1}$ and Zhibin Wang ${ }^{1}$ \\ ${ }^{1}$ Hubei Key Laboratory for Heavy Rain Monitoring and Warning Research, Institute of Heavy Rain, \\ China Meteorological Administration, Wuhan 430205, China \\ ${ }^{2}$ Nanjing University of Information Science and Technology, Nanjing 210044, China \\ ${ }^{3}$ State Key Laboratory of Severe Weather, Chinese Academy of Meteorological Sciences, Beijing 100081, China \\ Correspondence should be addressed to Hongli Li; lihongli@whihr.com.cn
}

Received 12 March 2018; Revised 29 May 2018; Accepted 31 May 2018; Published 28 June 2018

Academic Editor: Mario M. Miglietta

Copyright (C) 2018 Hongli Li et al. This is an open access article distributed under the Creative Commons Attribution License, which permits unrestricted use, distribution, and reproduction in any medium, provided the original work is properly cited.

\begin{abstract}
Operational Doppler radar observations have potential advantages over other above-surface observations when it comes to assimilation for mesoscale model simulations with high spatial and temporal resolution. To improve the forecast of a heavy frontal rainfall event that occurred in the Yangtze-Huaihe River Basin from 4 July to 5 July 2014 in China, operational radar observations are assimilated by the Local Analysis and Prediction System (LAPS). Radar reflectivity data are used primarily in the LAPS cloud analysis procedure, which retrieves the number of hydrometeors and adjusts the moisture and cloud fields. Radial velocity data are analyzed through the LAPS wind analysis-based successive correction method. A new correction method is developed to correct threedimensional radar reflectivity data based on hourly surface rain gauge observations. The performance of the correction method is demonstrated by assimilating radar reflectivity observations into LAPS. Experiments with different radar data assimilation are examined. Results show that the assimilation of radar data can effectively correct the background errors and improve the heavy rainfall forecast. The simulated intensity, pattern, and temporal evolution of the heavy rainfall event are better improved with radar reflectivity assimilation, especially when the correction method is implemented to correct radar observations.
\end{abstract}

\section{Introduction}

From mid-June to early July each year, accompanied with the northward advance of the East Asian summer monsoon, there always exists a period of seasonal rainfall maximum in the Yangtze-Huaihe River Basin between 28 and $34^{\circ} \mathrm{N}$ to the east of Yichang in China. Rainfall during this period is called "Meiyu" in China and "Baiu" in Japan, since this period corresponds to the maturing season of plums. Flood disasters in the Yangtze-Huaihe River Basin triggered by rainstorms along the Meiyu front in the middle and lower reaches of the Yangtze River are among the most important meteorological disasters in China. Due to the special characteristics of synoptic background, mesoscale structure, multiscale system interaction, and triggering and maintenance mechanisms for the Meiyu frontal rainstorms, monitoring and forecasting the Meiyu frontal rainstorms is a difficult issue that attracts great attention of meteorologists in China.
Quantitative precipitation forecast (QPF) associated with Meiyu frontal rainstorm remains a key challenge for numerical models. Many studies have been conducted to explore various aspects of the Meiyu frontal storm, such as synoptic scale physical mechanisms for the storm [1], changes of the Meiyu system in the context of global warming [2], uncertainties and physical mechanisms for mesoscale convective systems to trigger heavy Meiyu frontal rainfall [3], impacts of urban expansion on precipitation during the Meiyu period [4], convergence of convective clouds during the heavy Meiyu frontal rainfall process [5], and simulations of Meiyu frontal rainstorms in the middle and lower reaches of the Yangtze River associated with mesoscale vortex [6].

With more and more Doppler radar deployment, realtime observational data become increasingly rich. In addition, Doppler radar can provide huge amounts of detailed information with high spatial and temporal resolution 
including three-dimensional clouds, wind and precipitation, which makes it possible to further improve the Meiyu frontal rainstorm forecast. Assimilating radar data into highresolution numerical models to improve short-term quantitative precipitation forecast has been a hot research topic worldwide in recent years [7-12].

Variables obtained from direct radar observations include radial velocity and reflectivity. Radar reflectivity reflects a variety of hydrometeors, which usually have a relatively short forecast valid period. Methods of assimilating radar reflectivity include direct, indirect, and transitional assimilation. With the indirect assimilation method, variables that can be adopted by numerical models are retrieved from radar observations first. For example, precipitation is first estimated by radar reflectivity, and condensational heating retrieved by precipitation is then forced to be adopted in numerical models using the Newton relaxation approximation method [13]. Direct assimilation means that radar reflectivity is directly assimilated into numerical models as a model variable using variational assimilation method [14] or ensemble Kalman filter method [15-17]. Transitional assimilation includes two types of assimilation. One is to accomplish the radar reflectivity assimilation in two steps; that is, a simple one-dimensional variational method is used first to retrieve a model forecast variable from radar observations, and a three-dimensional or four-dimensional variational assimilation system is then utilized to assimilate the retrieved variable $[18,19]$. The other is to assimilate radar reflectivity by a cloud analysis procedure, such as the cloud analysis system in the Local Analysis and Prediction System (LAPS), to provide the initial condition that is not only dynamically and thermally consistent but also contains cloud microphysical variables to improve short-term quantitative precipitation forecast $[11,20,21]$.

No matter what method is used for assimilation of radar reflectivity, the prerequisite is that radar reflectivity observational data must be accurate enough and the effective detection range should cover the model forecast domain. The operational Doppler weather radars located in China have different wavebands in the east and west. The western and eastern regions are dominated by the C-band and $S$-band radars, whose wavelengths are $5 \mathrm{~cm}$ and $10 \mathrm{~cm}$, respectively. Although radars produced by different manufacturers have the same band, there are differences in their spatial resolutions and data format. This may impair the quality of radar observations and thus affect the assimilation in numerical models. Large amounts of rainfall observations collected at surface stations located within the region of China Mesoscale Observation Network can well compensate for possible missing information in the radar blind zone. The relationship between precipitation intensity $I$ and radar reflectivity $Z$ is the basis for quantitative radar measurement of precipitation. A new correction method based on the relationship between $Z$ and $I$ is developed to correct threedimensional radar reflectivity data using hourly surface rain gauge observations. Assimilation experiments on a mudslide rainstorm show that this method can improve the capability of radar reflectivity assimilation and thus yield better heavy rainfall forecasts [22].
LAPS, developed and operated by Earth System Research Laboratory of National Oceanic and Atmospheric Administration (NOAA) in Boulder, Colorado, combines a wide array of observed meteorological datasets into a unified atmospheric analysis with a time interval of an hour or less. It is also a mesoscale meteorological data assimilation tool that employs a suite of observations (meteorological networks, radar, satellite, soundings, and aircraft) to generate a realistic, spatially distributed, time-evolving, threedimensional representation of atmospheric features and processes [20, 23-26]. LAPS can serve as a tool to initialize local-scale mesoscale weather forecast models over local to regional domains [27-29]. Because it provides cloud ice, cloud water, rain, snow, and graupel analysis to initialize forecast models, LAPS can be used to provide a hot start for operational forecast models [20].

Since 2006, the Institute of Heavy Rain (IHR) has been collaborating with NOAA/ESRL to develop the application method of LAPS in China [30]. The wind and humidity fields have been improved greatly with the input of wind profile radars and GPS observations into LAPS [31-33]. Even though when sometimes the radar observation of China was assimilated by LAPS, there were no satisfactory effects because of the difference in the resolution of radar observations at different wavelengths. In this study, we attempt to adopt a new correction method to use the hourly surface rain gauge observations to correct the radar reflectivity factors, and study the impact of China radar observation assimilated by LAPS to a Meiyu frontal rainstorm forecast with WRF. It may improve the local rainstorm forecast if this method is applied in operation. We use LAPS to assimilate observations to a hot start of WRF. Numerical experiments are performed to simulate a heavy Meiyu frontal rainfall case and explore the sensitivity of radar data assimilation. The impact of the radar data assimilation with the correction method on the prediction of a heavy rainfall event is demonstrated. In Section 2, we describe the data and the correction method, the model and its configuration, the experiments used to assimilate radar observations, and the heavy rainfall case selected for the present study. Section 3 presents the results, and the summary and conclusions are given in Section 4.

\section{Data and Methodology}

2.1. Data Description. The types of operational Doppler radar in China include C-band and S-band, which are deployed in different provinces. Figure 1(a) shows the model domain and locations of various types of Doppler radar sites. In the present study, 83 radars are used, including 7 SC radars, $13 \mathrm{CD}$ radars, $5 \mathrm{CC}$ radars, $6 \mathrm{CB}$ radars, and $52 \mathrm{SA}$ and SB radars. The first letter of the radar type acronyms means S-band or C-band. The second letter means the different radar manufacturers in China. Both S-band and C-band operational Doppler weather radars are operating in two volume coverage patterns (VCPs) to sample precipitating systems. VCP11 provides 14 unique elevation scans every 5 minutes, while VCP21 provides 9 unique elevation scans every 6 minutes, for elevation angles of $0.5^{\circ}$ 


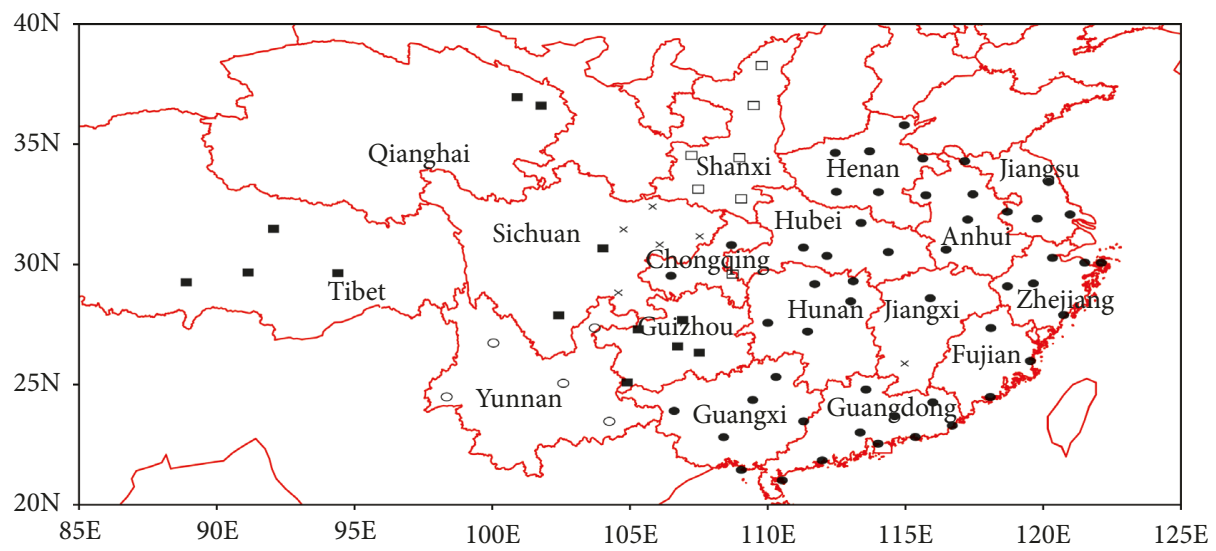

(a)

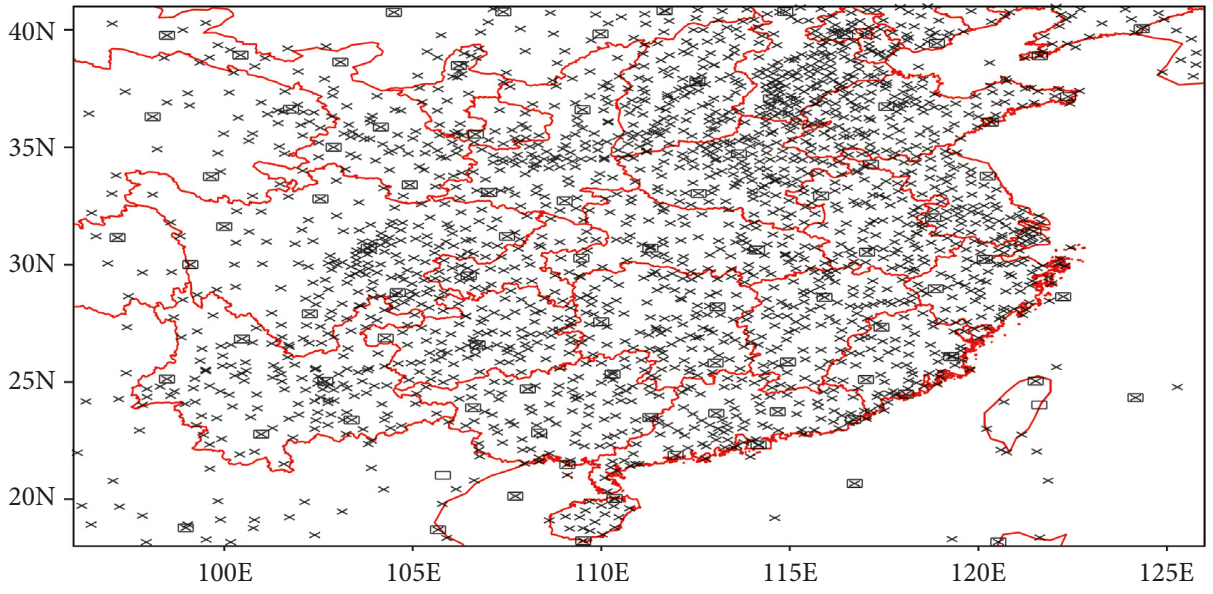

(b)

FIgURE 1: (a) Locations of Doppler radar sites in China (black solid circle, hollow circle, solid square, hollow square, and $\times$ refer to SA/SB, $\mathrm{CB}, \mathrm{CD}, \mathrm{CB}$, and SC, respectively), and (b) radiosonde (black hollow square) and surface meteorological sites $(\times)$.

through $19.5^{\circ}$. The observation variables of all the operational Doppler radars are same including radar reflectivity, radial velocity, and wide spectrum, but there are differences in spatial resolution and data format.

To ensure the quality of these observations, the singleradar measurements, such as radar reflectivity and radial velocity, have gone through strict quality control including calibration, nonmeteorological return filtering, and velocity dealiasing by the Severe Weather Automatically Nowcast System (SWAN) developed by China Meteorological Administration, which operates on multiple radars to yield real-time observations and products for severe weather nowcasting [34-36]. Then, the operational Doppler radar observation data of different types are unified to the same data format required by LAPS. Finally, a new correction method is used to correct the radar reflectivity factors.

In addition to Doppler radar data, other observations used in this study include data from 79 radiosonde sounding sites and 2049 surface meteorological sites (Figure 1(b)). The variables of radiosonde observations include pressure, height, temperature, dew point, wind direction, and wind speed at significant levels at each site. The vertical levels include $1000 \mathrm{hPa}, 925 \mathrm{hPa}, 850 \mathrm{hPa}, 700 \mathrm{hPa}, 500 \mathrm{hPa}$,
$400 \mathrm{hPa}, 300 \mathrm{hPa}, 250 \mathrm{hPa}, 200 \mathrm{hPa}, 150 \mathrm{hPa}$, and $100 \mathrm{hPa}$. The variables of surface meteorological observations include pressure, temperature, dew point, wind direction, and wind speed. Surface rain gauge observations are used for the verification of model simulation results.

2.2. Description of the Correction Method. Li and Xu [22] introduced in detail a correction method to correct radar reflectivity using hourly surface rain gauge data. Figure 2 shows the diagram of the method with LAPS in this study. Observations of radar reflectivity are interpolated into LAPS three-dimensional $(x, y, z)$ grids to obtain the radar reflectivity $Z_{\text {LAPS }}(x, y)$ at grids within the LAPS domain. Optimum coefficients in the dynamic relationship of $Z-I$ are identified using the hourly surface rain gauge observations and radar reflectivity at each level. Suppose that each hourly rainfall $I_{\mathrm{G}}(I, J)$ at the surface station $(I, J)$ corresponds to the radar reflectivity $\mathrm{dBZ}$, then $\mathrm{dBZ}$ can be used to derive rainfall intensity based on the relationship between radar reflectivity and rainfall intensity, that is, $Z=a I^{\mathrm{b}}$. Hourly precipitation $I_{\mathrm{R}}(I, J)$ estimated from radar observations can be obtained by time integration of the estimated rainfall 


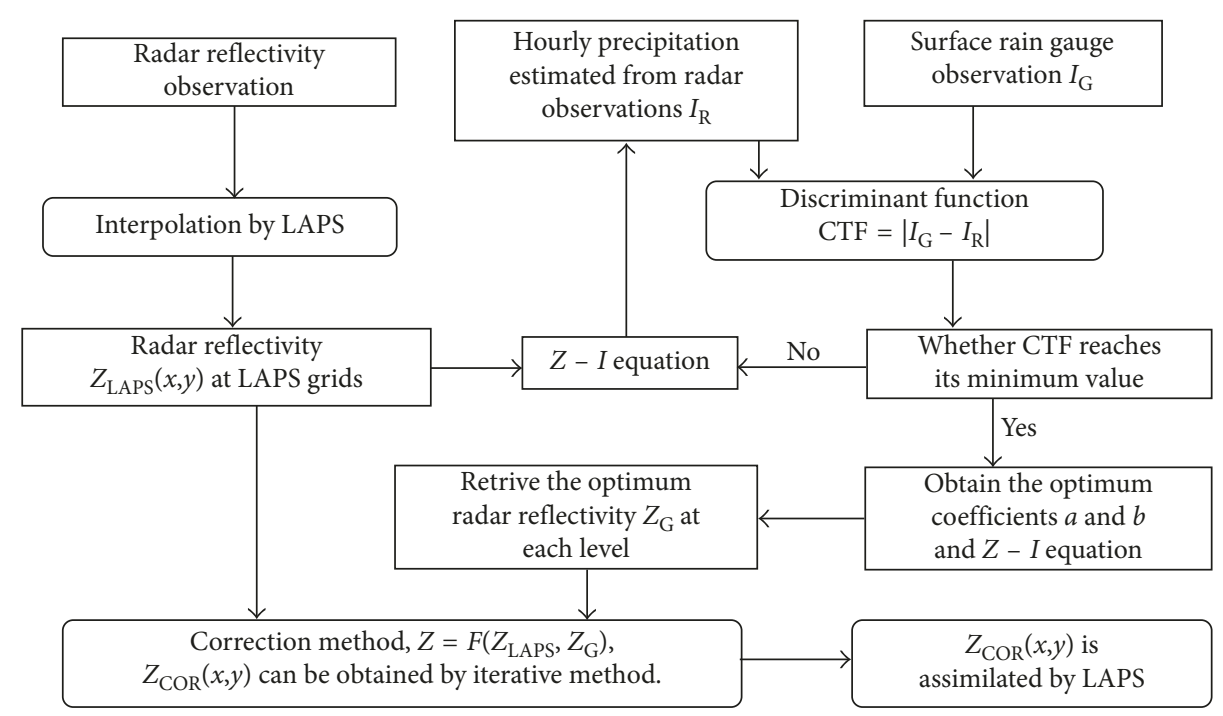

FIGURE 2: Diagram of the correction method to correct radar reflectivity using hourly surface rain gauge observations.

intensity. To obtain the optimum coefficients $a$ and $b$, the discriminant function $\mathrm{CTF}=\sum\left|I_{\mathrm{G}}-I_{\mathrm{R}}\right|$ is defined. Initial values of $a$ and $b$ are specified first, and these values then change within a certain range. When CTF reaches its minimum value, the corresponding values of $a$ and $b$ are the optimum values we seek. Based on the optimum coefficients of $a$ and $b$ at each level, the $Z-I$ relationship, and hourly rainfall observations $I_{\mathrm{G}}(I, J)$, we can retrieve the radar reflectivity $Z_{\mathrm{G}}(I, J)$ at each level above the corresponding surface station. Based on $Z_{\mathrm{G}}(I, J), Z_{\mathrm{LAPS}}(x, y)$ is corrected by using the correction method, and the three-dimensional radar reflectivity $Z_{\mathrm{COR}}(x, y)$ can be obtained by iterative method. Finally, we use LAPS to assimilate $\mathrm{Z}_{\mathrm{COR}}(x, y)$ to perform the numerical experiments.

2.3. Case Overview and Design of Experiments. Affected by the slow eastward movement of the low-level southwest vortex and the shear line over the Meiyu front, the first heavy Meiyu frontal rainfall in the Yangtze-Huaihe River Basin ranges from 4 July to 5 July 2014. The observed $24 \mathrm{~h}$ accumulated precipitation is shown in Figure 3(a). The rain belt was oriented from southwest to northeast. The heavy rainfall area was mainly located in Hubei, Anhui, and Jiangsu provinces (the red box shown in Figure 3). Several obvious rainfall centers with $24 \mathrm{~h}$ accumulated precipitation amount greater than $100 \mathrm{~mm}$ were found along the rain belt. The $24 \mathrm{~h}$ maximum of $297 \mathrm{~mm}$ was located at Yuexi in Anhui Province. The heavy rainfall event lasted for a long period and covered a large area, causing a severe flooding along the Yangtze River and tremendous economic losses.

The mesoscale nonhydrostatic Weather Research and Forecast (WRFV3.4.1) model is used in this study. LAPS is utilized to assimilate observations. We evaluate the performance of radar data assimilation mainly by examining the accuracy of the subsequent forecast. The primary goal of this work is to test the impact of assimilation of operational Doppler radar observations into initial conditions on the forecast of heavy rainfall events. Three experiments are conducted for the case study. In the control experiment $(\mathrm{CON})$, radiosonde and surface meteorological observations are assimilated. Besides radiosonde and surface observations, operational Doppler radar observations are assimilated in the other two experiments (RAD and RADC). The difference between these two experiments is whether the correction method is used to correct radar reflectivity. The method is implemented in RADC but not in RAD. The horizontal grid resolution of the WRF model is $9 \mathrm{~km}$. There are 45 levels in the vertical and the model top is $50 \mathrm{hPa}$. The model domain covers an area of $2000 \mathrm{~km} \times 2000 \mathrm{~km}$. The initial and lateral boundary fields of all experiments are extracted from the National Centers for Environmental Prediction (NCEP) Global Data Assimilation System (GDAS) Final Operational Global Analyses $\left(1^{\circ} \times 1^{\circ}\right)$. Important physics schemes used in the present study include the WSM6 microphysics scheme, the YSU planetary boundary layer scheme, the Kain-Fritsch cumulus parameterization scheme, the Rapid Radiative Transfer Model longwave radiation scheme, and the Dudhia shortwave radiation scheme. The model is integrated for 24 hours from 00 UTC 4 July to 00 UTC 5 July 2014.

\section{Results}

3.1. Simulation of Precipitation. There existed a northeastsouthwest-oriented rainfall belt (black solid box) in this heavy rainfall event. The key rainstorm area with $24 \mathrm{~h} \mathrm{ac}$ cumulated precipitation amount exceeding $100 \mathrm{~mm}$ was mainly located in eastern Hubei, and central and southern Anhui (denoted by the red solid box shown in Figure 3(a)). Comparison of the $24 \mathrm{~h}$ accumulated precipitation simulated by the three experiments with the rainfall observations shows that all the three experiments can realistically reproduce the location of the main rainfall belt, and the strongest precipitation area is located in the lower reaches of the Yangtze River. However, there are obvious differences in rainfall intensity between the simulations and observations. 


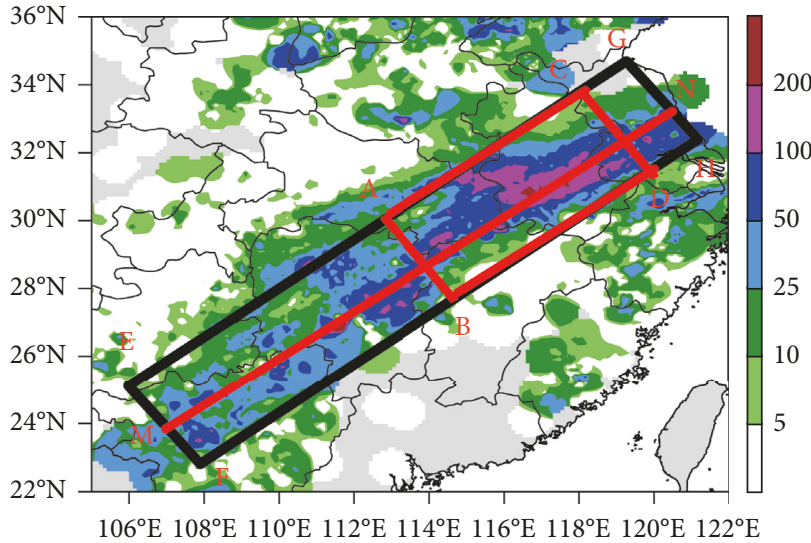

(a)

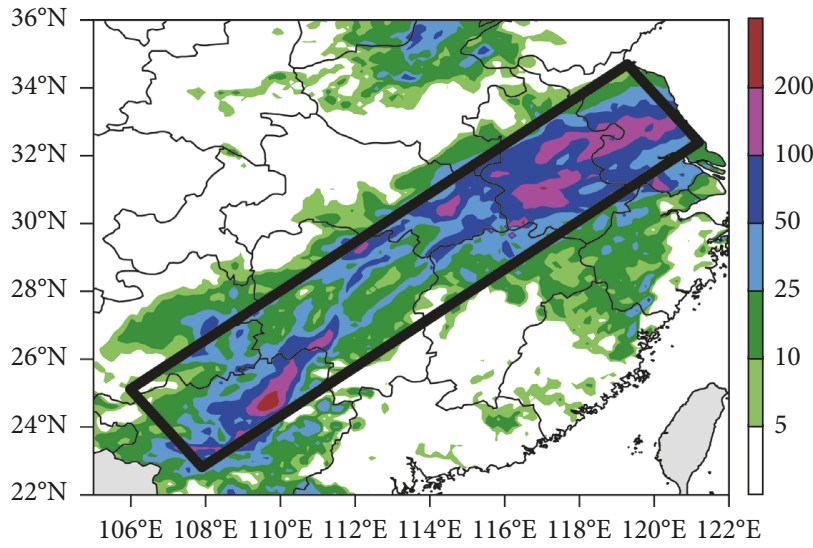

(c)

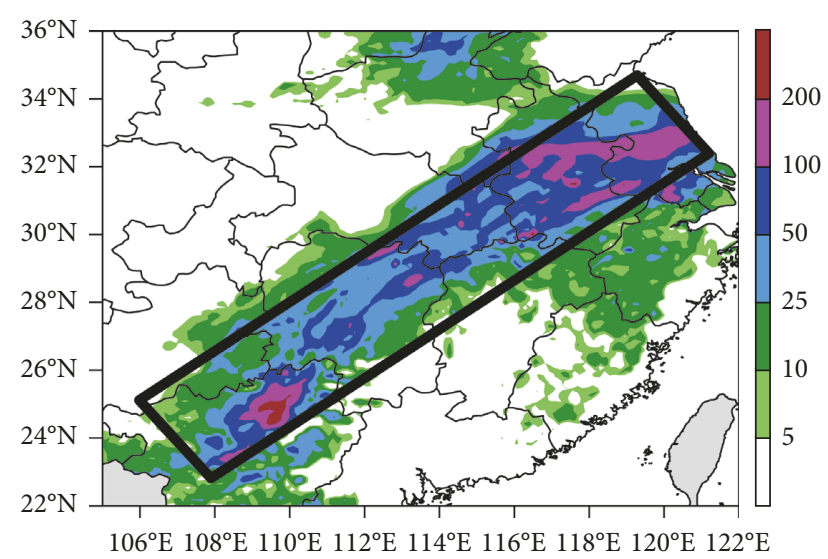

(b)

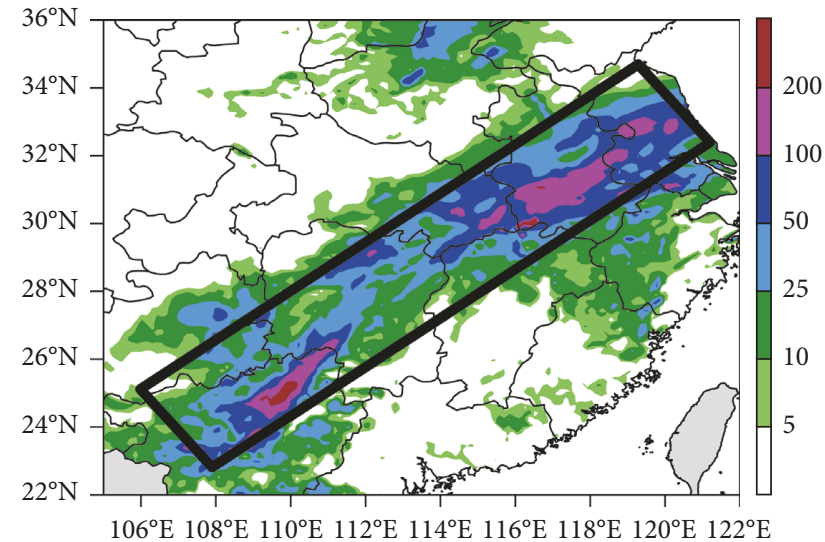

(d)

FIgURE 3: Twenty-four-hour accumulated precipitation for the period 0000 UTC 4 July to 0000 UTC 5 July 2014 from observations (a) and simulations in (b) CON, (c) RAD, and (d) RADC (unit: mm). The black and red solid boxes represent the main rainfall belt and the key rainstorm area with $24 \mathrm{~h}$ accumulated precipitation amount greater than $100 \mathrm{~mm}$, respectively.

CON fails to reproduce the strongest center of heavy rain in central Anhui, and the simulated heavy rainfall area is located to the northeast of the observed heavy rainfall region (Figure 3(b)). RAD can well simulate the heavy rainfall center located in central Anhui, but it creates larger area receiving rainfall than observations (Figure 3(c)). The rainstorm simulated in RADC experiment is similar to observations in terms of location and intensity, and RADC can successfully correct the overestimation of precipitation in Jiangsu found in the other two experiments (Figure 3(d)).

Regarding the temporal evolution of observed $6 \mathrm{~h}$ accumulated rainfall from 00 UTC 4 July to 00 UTC 5 July 2014, the rainfall amount of the first 6 hours over the key rainstorm area located in eastern Hubei and Anhui is pretty large, and the largest rainfall amount at the rainstorm center is above $50 \mathrm{~mm}$ (Figure 4(a)). The accumulated rainfall in the second 6-hour interval is weak, and the rainfall area extends eastward (Figure 4(b)). The $6 \mathrm{~h}$ accumulated rainfall amount begins to increase again from 12 UTC to 18 UTC (Figure 4(c)). The strongest precipitation over the key rainstorm area occurs in the last 6 hours (Figure 4(d)). Comparing the temporal evolution of $6 \mathrm{~h}$ accumulated precipitation simulated in the three experiments with observations, it is clear that the RADC simulation is the closest to observations. The first $6 \mathrm{~h}$ rainfall amount over the key rainstorm area simulated in RADC is larger than that in the other two experiments, and the rainfall amount of the precipitation center is greater than $50 \mathrm{~mm}$. The precipitation weakens six hours later and starts to increase with time 12 hours later (Figures $4(\mathrm{~m})-4(\mathrm{p}))$. In CON, the $6 \mathrm{~h}$ rainfall amount keeps increasing with time (Figures $4(\mathrm{e})-4(\mathrm{~h})$ ). The rainstorm center is located to the east of the observed center. The rainfall belt moves faster, and the rainfall amount is larger than observations. The evolution of $6 \mathrm{~h}$ precipitation simulated in RAD is better than that in CON. RAD reproduces the strong-weak-strong precipitation variation, which is similar to observations. However, the location of the rainstorm center simulated in RAD is located to the northeast of the observed center, which is worse than the simulation in RADC (Figures 4(i) $-4(\mathrm{l})$ ).

To compare the temporal evolutions of the rainfall belt between observations and simulations of the three experiments, we calculate hourly rainfall averaged over the area indicated by black solid box along line EF (Figure 3(a)) direction. Time series of hourly average rainfall along line $\mathrm{FH}$ direction (shown in Figure 3(a)) are presented in Figure 5. 


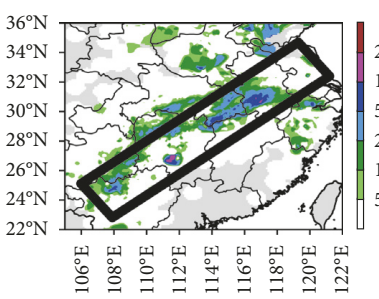

(a)

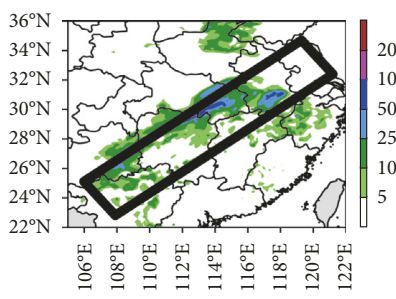

(e)

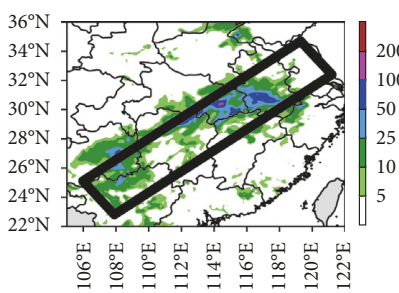

(i)

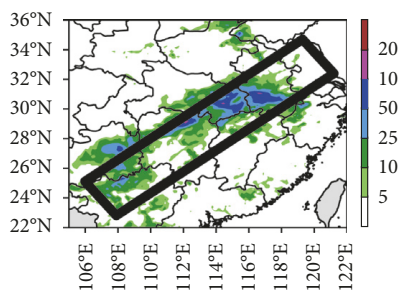

$(\mathrm{m})$

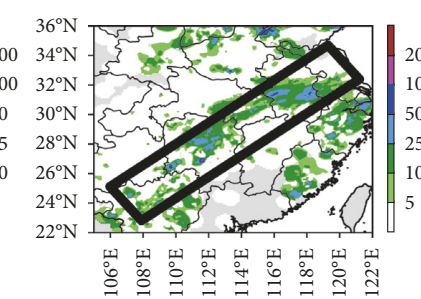

(b)

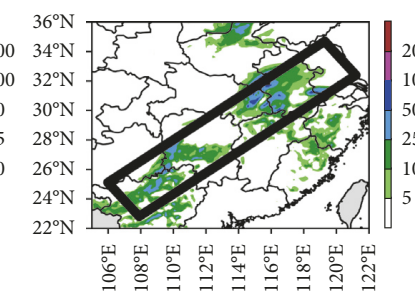

(f)

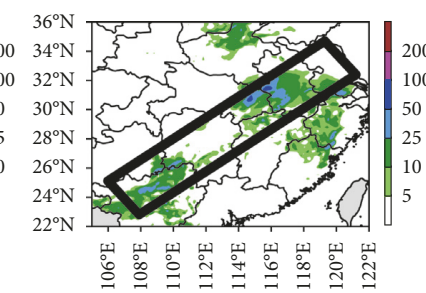

(j)

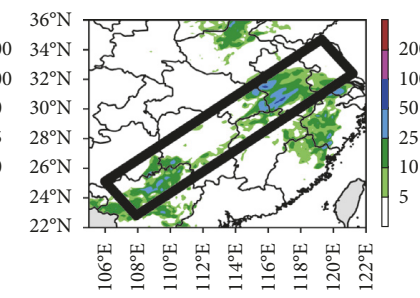

(n)

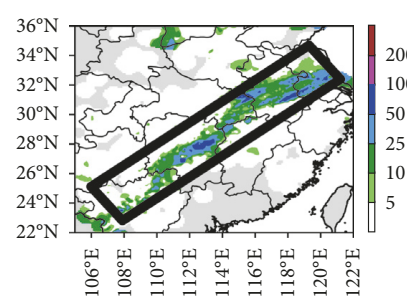

(c)

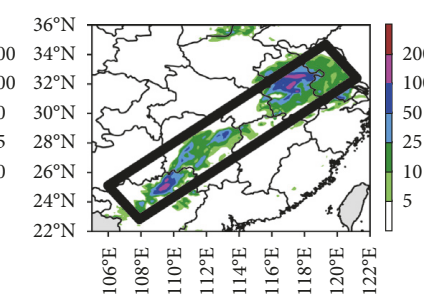

(g)

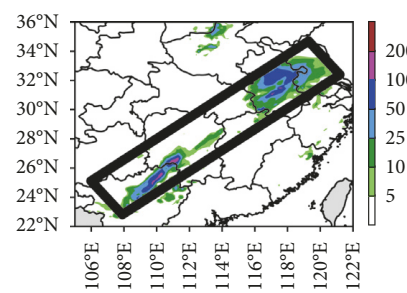

(k)

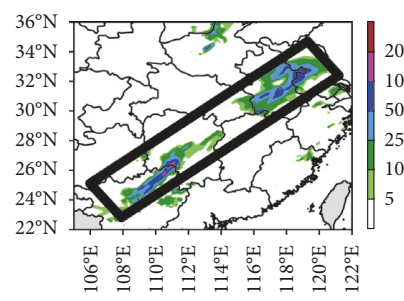

(o)

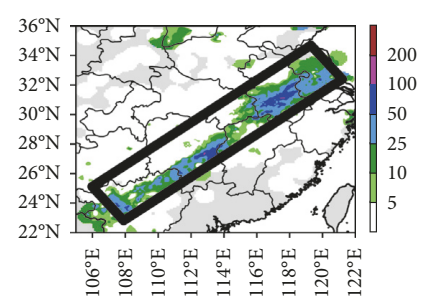

(d)

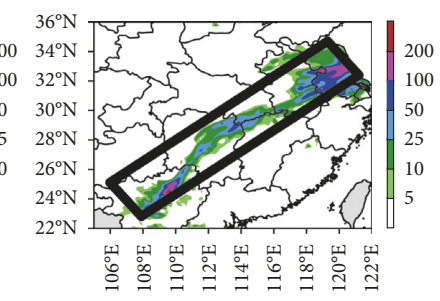

(h)

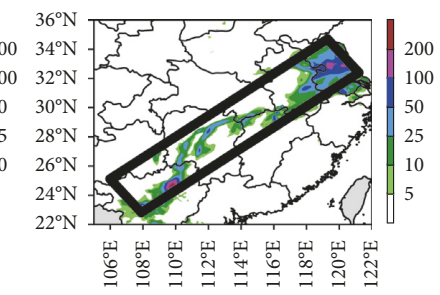

(1)

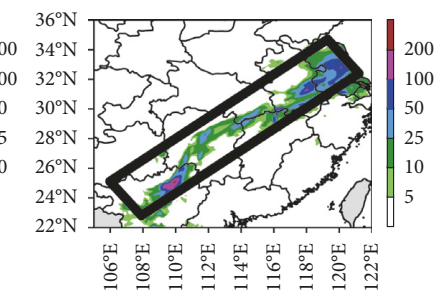

(p)

FIGURE 4: Six-hour accumulated precipitation from 0000 to 0600 UTC ((a) observations, (e) CON, (i) RAD, and (m) RADC) and from 0600 to 1200 UTC ((b) observations, (f) CON, (j) RAD, and (n) RADC), from 1200 to 1800 UTC ((c) observations, (g) CON, (k) RAD, and (o) RADC), and from 1800 UTC 4 July to 0000 UTC 5 July 2014 ((d) observations, (h) CON, (l) RAD, and (p) RADC) (unit: mm). The black solid squares represent the main rain belt.

Observations (Figure 5(a)) show clearly that the disperse heavy rainfall occurred in the southwestern area, and the rainfall in the northeastern area (red box) corresponds to temporal evolution of the heavy rainfall averaged over the key rainstorm area (red box in Figure 3(a)). Rainfall over this region is mainly concentrated over two periods: $0-8$ hours and 14-24 hours. CON fails to reproduce the two precipitation periods, and the rainfall in the later period is heavier than observations (Figure 5(b)), while RAD and RADC with radar data assimilation can reproduce the two rainfall periods similar to observations. The simulated hourly precipitation amount over the later period in RAD is too high, and the evolution of rainfall simulated in RADC is closer to observation than that in RAD (Figures 5(c) and 5(d)).

Time series of hourly average precipitation over the key rainstorm area from observations and three experiments are displayed in Figure 6, which shows that all the three experiments can well simulate the two rainfall periods in this key area.
Here, OBS refers to the hourly surface rain gauge observations. The rainfall intensity in the first period simulated in RAD and RADC with radar data assimilation is larger and that in $\mathrm{CON}$ is smaller than observation, while the rainfall intensity in the second period is better simulated in RAD and RADC than in CON. In particular, the evolution of hourly rainfall simulated in RADC is consistent with observations (Figure 6(a)). From the time series of hourly rain rate with various intensities, it can be found that the evolution of light rainfall (i.e., rain rate is less than $5 \mathrm{~mm} / \mathrm{hr}$ ) in the three experiments is similar to observations (Figure 6(b)). Simulations of moderate and heavy rainfall in RAD and RADC are better than that in CON, and the heavy rainfall simulation is the best in RADC, which yields comparable results with observations (Figures 6(c) and 6(d)). The above results indicate that radar data assimilation can well improve the simulation of rainfall, while the assimilation of radar reflectivity corrected by the correction method can better improve the simulation of heavy rainfall. 


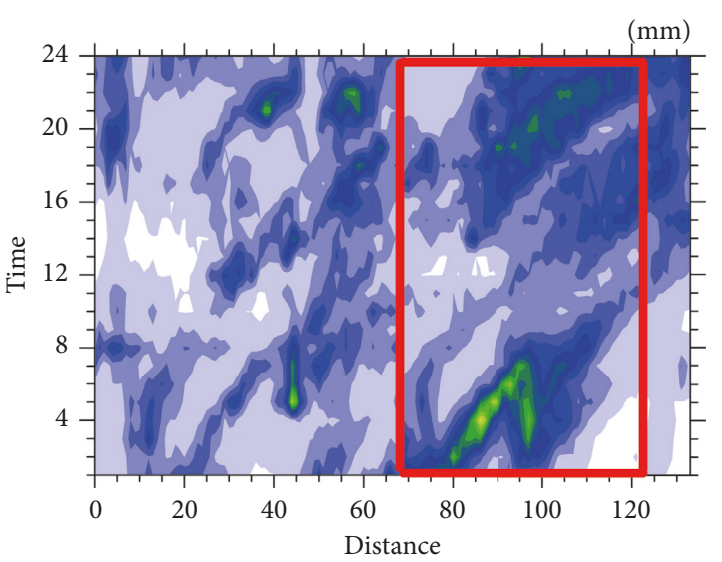

(a)

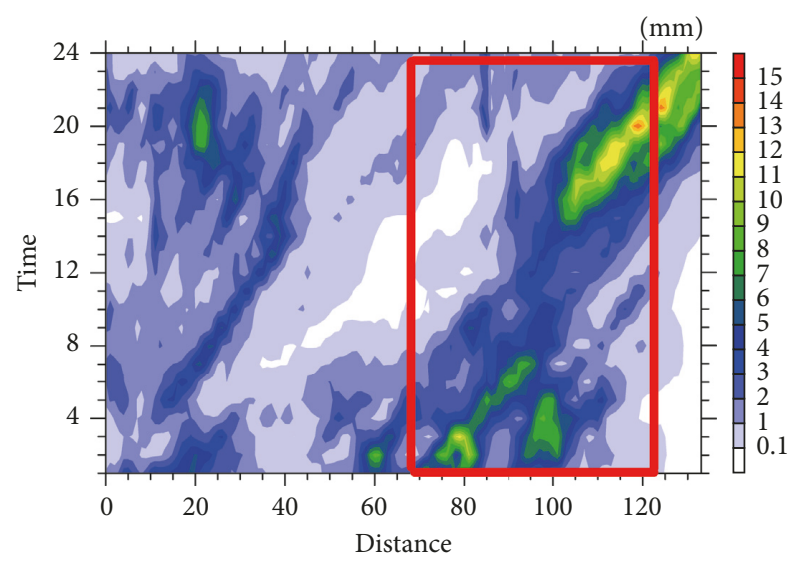

(c)

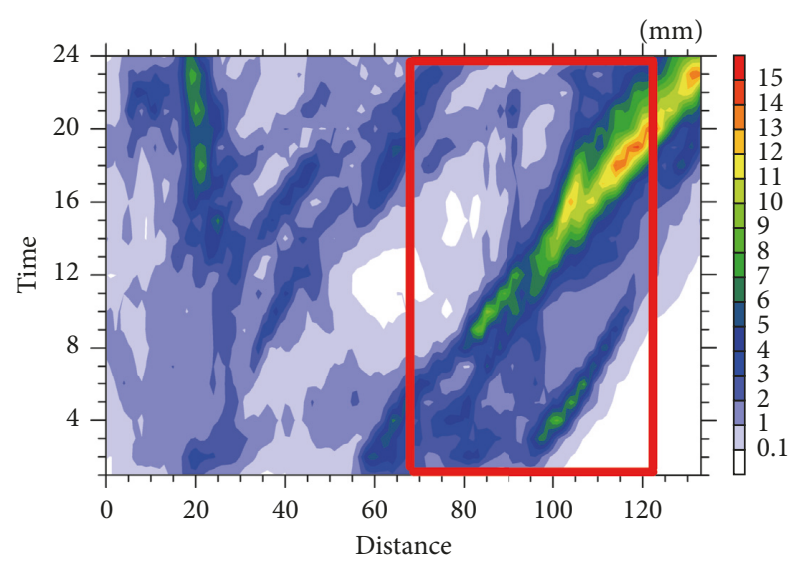

(b)

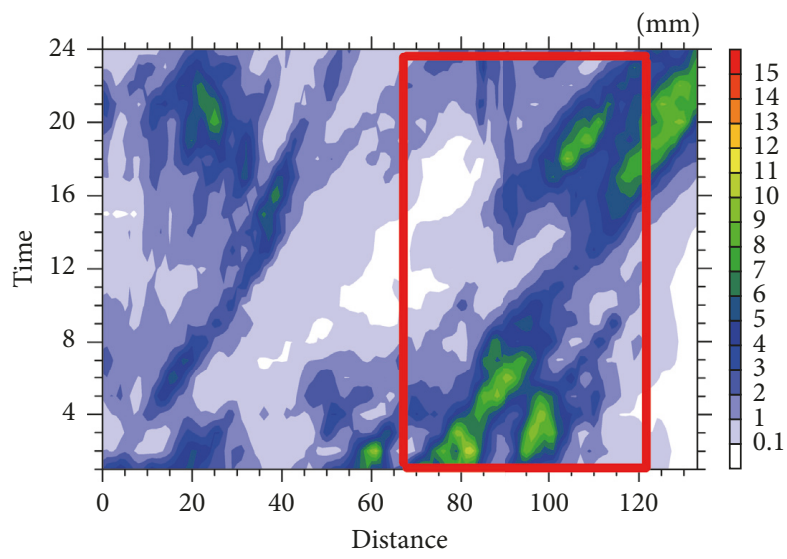

(d)

FIgURE 5: Time-distance cross sections along line EF direction (shown in Figure 3(a)) of hourly rainfall averaged along line FH direction (Figure 3(a)) in the rainfall belt from 0000 UTC 4 July to 0000 UTC 5 July 2014: observations (a) and simulations in (b) CON, (c) RAD, and (d) RADC (unit: $\mathrm{mm} / \mathrm{hr}$ ). The red solid box represents temporal evolution of rainfall over the key rainstorm area (red box in Figure 3(a)). The horizontal axis is the distance from line EF (Figure 3(a)) (unit: $10 \mathrm{~km}$ ). The vertical axis is the forecast hours.

In summary, the simulated characteristics of precipitation distribution of this heavy rainfall event indicate that the three numerical experiments can realistically reproduce the southwestern-northeast precipitation belt. The simulations are close to observations, and the two rainfall periods over the key rainstorm area are well described, too. However, there exist certain differences between the simulated and observed location and intensity of heavy rainfall center. It is found that the initial background field and boundary conditions used in the experiments can reflect the large-scale background circulation during the heavy rainfall event, and the assimilation of observational data can adjust the initial condition of the model, which improves the simulation of the evolutional characteristics of the rainstorm system. The characteristics of rainfall distribution and evolution with time simulated in RAD and RADC with assimilation of radar data are better than that simulated in CON. Since the correction method is used to correct radar reflectivity based on hourly surface rain gauge observations in RADC, the location and intensity of heavy rainfall simulated in RADC are consistent with rainfall observations and better than that simulated in RAD. These results show that the assimilation of radar data can effectively correct the location errors in the background and improve the simulation of the heavy rainfall in the numerical model. The heavy rainfall simulated in RADC is the closest to observations in terms of the location, intensity, and evolution of rainfall with time. The overestimation of rainfall in the other two experiments is successfully corrected in RADC.

3.2. Analysis of Initial Conditions. In order to explore the reasons for the improvement of the simulation of this rainfall event by radar data assimilation, the initial conditions of the three experiments are compared and analyzed. Figure 7 presents the initial fields of the three numerical experiments at 00 UTC 4 July 2014. The initial condition of wind and relative humidity fields at $700 \mathrm{hPa}$ and geopotential height at $500 \mathrm{hPa}$ for CON (Figure 7(a)) shows that the precipitation area (red box) is located in front of the upper trough, where relative humidity is high. Rainfall is affected by an eastward-moving low vortex and low-level shears, and the rainfall area is underneath the region dominated by the southwesterly low-level jet stream (LLJ). 


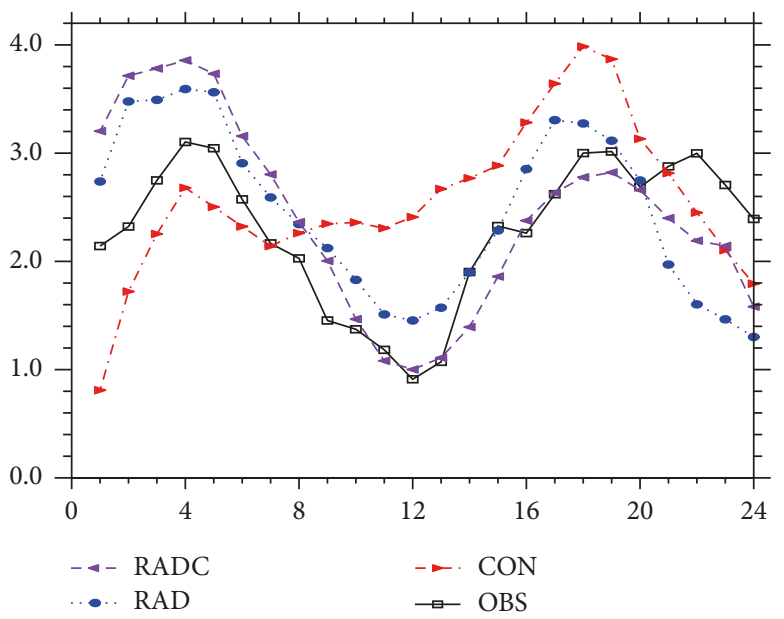

(a)

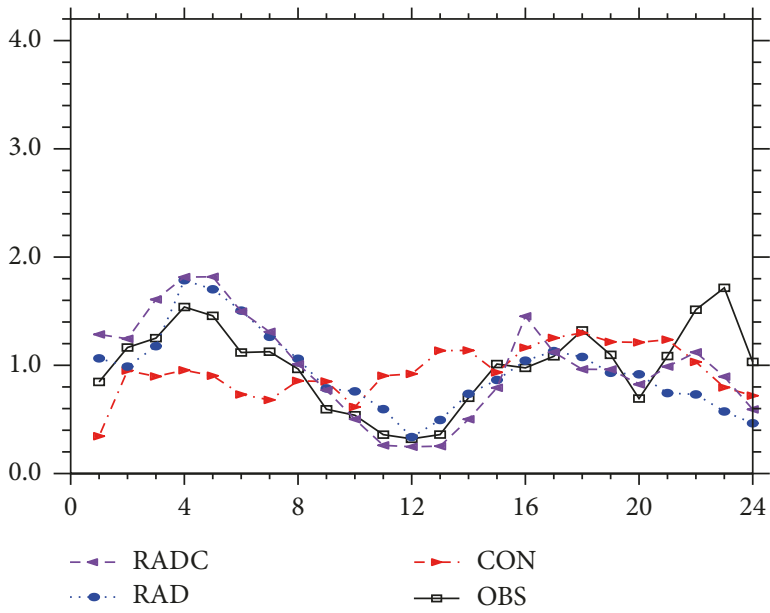

(c)

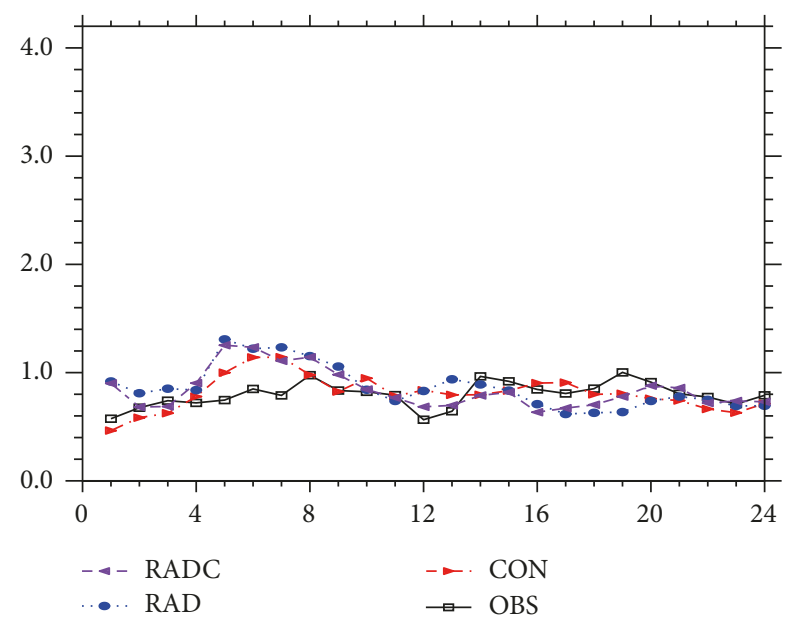

(b)

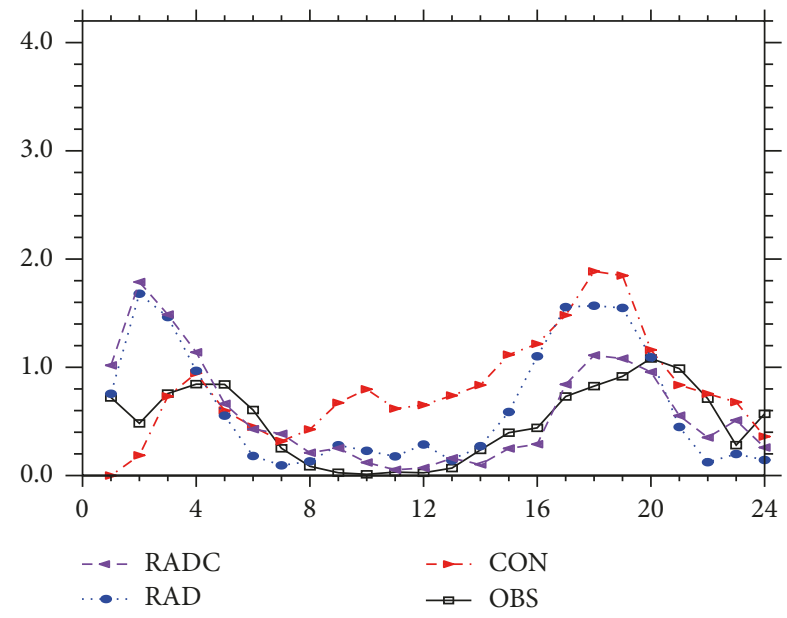

(d)

Figure 6: Time series of hourly average precipitation over the key rainstorm area from observations (solid line, black) and simulations of three experiments (dashed lines) (a) (unit: $\mathrm{mm} / \mathrm{hr}$ ). (b), (c), and (d) are the same as (a) but for the rain rates less than $5 \mathrm{~mm} / \mathrm{hr}$, greater than $5 \mathrm{~mm} / \mathrm{hr}$ and less than $15 \mathrm{~mm} / \mathrm{hr}$, and greater than $15 \mathrm{~mm} / \mathrm{hr}$, respectively. The horizontal axis is forecast hours from 0000 UTC 4 July to 0000 UTC 5 July 2014.

Compared with the initial condition for CON (Figure 7(a)), the southwesterly LLJ is stronger in the initial conditions for RAD and RADC (Figures 7(b) and 7(c)). Radar data assimilation promotes the transport of water vapor to the heavy rainfall area, which is favorable for the maintenance and development of the rainstorm system. Comparing the wind fields in initial conditions for RAD and CON shown in Figure $7(\mathrm{~d})$, it is obvious that the wind speed in the precipitation area (red box) is increased by $6 \mathrm{~m} / \mathrm{s}$ and the southwesterly wind component is also increased by radar data assimilation. Difference of specific humidity in initial conditions between RADC and RAD shows that the specific humidity is slightly increased by $1 \mathrm{~g} / \mathrm{kg}$ with the correction of radar reflectivity. The above results suggest that the southwesterly low-level jet stream in the rainstorm area is enhanced by assimilating radial wind data, and the correction of radar reflectivity is helpful to increase humidity over the rainstorm area. The initial background fields are adjusted to be more realistic due to radar data assimilation, providing favorable environmental conditions for the development and maintenance of the rainstorm system.

The LAPS cloud analysis system has been updating microphysical variables for decades [20]. It also adjusts the humidity field based on observational data. In this study, the increments of cloud microphysical variables are analyzed to evaluate the impact of radar data assimilation. Figure 8 shows cross sections of radar echo, humidity, and increments of cloud hydrometeors along line MN (shown in Figure 3(a)) at the initial time due to radar data assimilation. At 0000 UTC 4 July 2014, several strong radar echoes are distributed along the cross section shown in Figure 8. The strongest radar echo is located in the key rainstorm area (the red box in Figure 3(a)). From Figure 8(a), it can be seen that positive differences in radar echo between initial conditions for RADC and RAD are mainly located in the key rainstorm area, and the difference extends upward from surface to the middle troposphere (Figure 8(a)). This result indicates that radar echoes over the rainstorm area are enhanced by using 


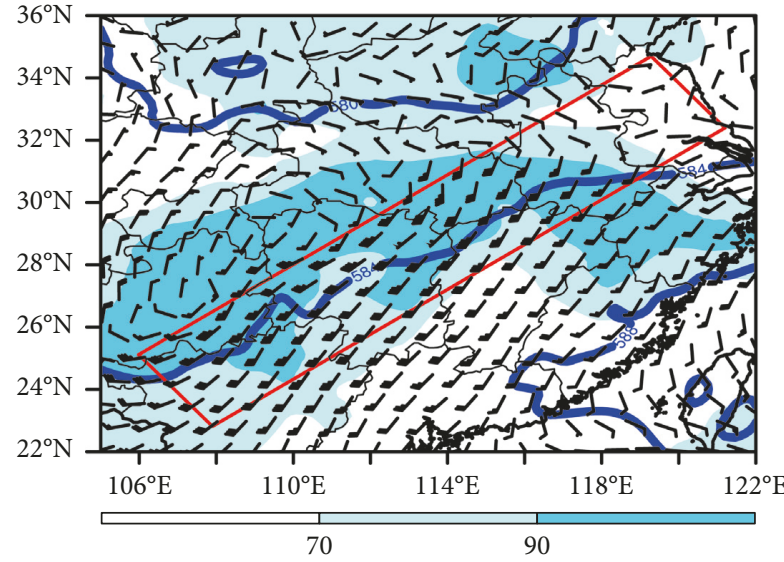

(a)

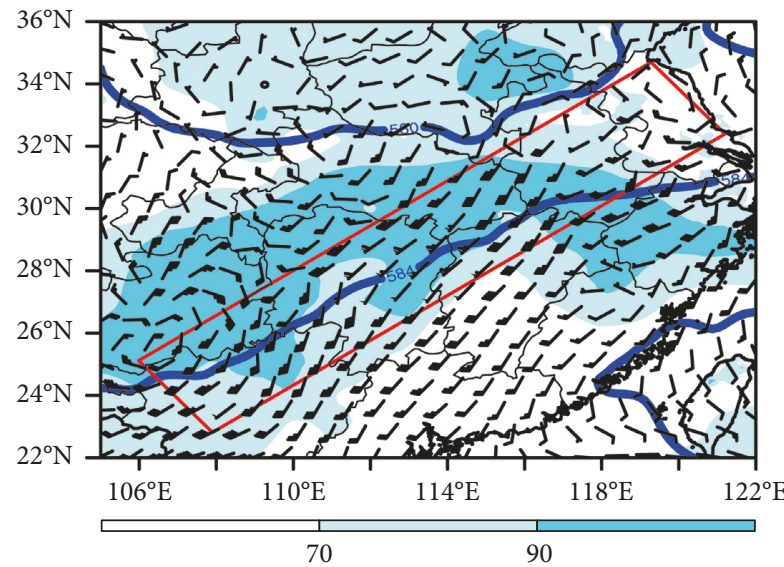

(c)

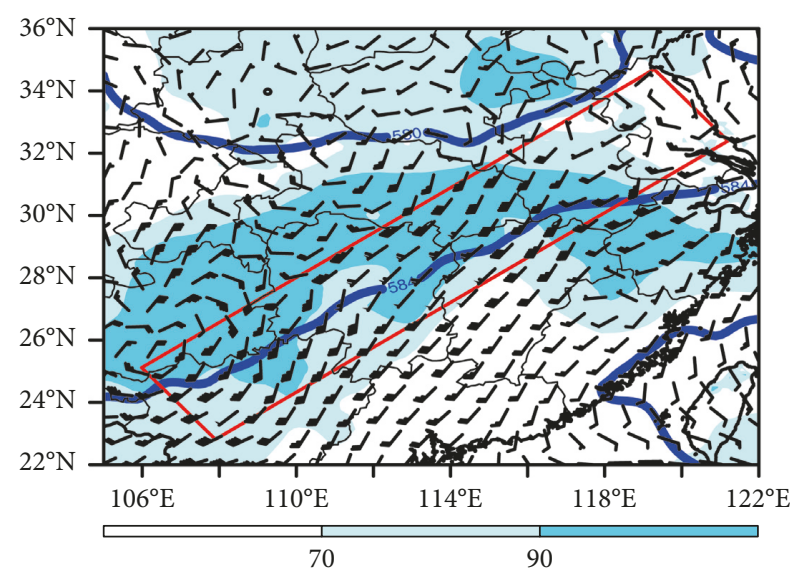

(b)

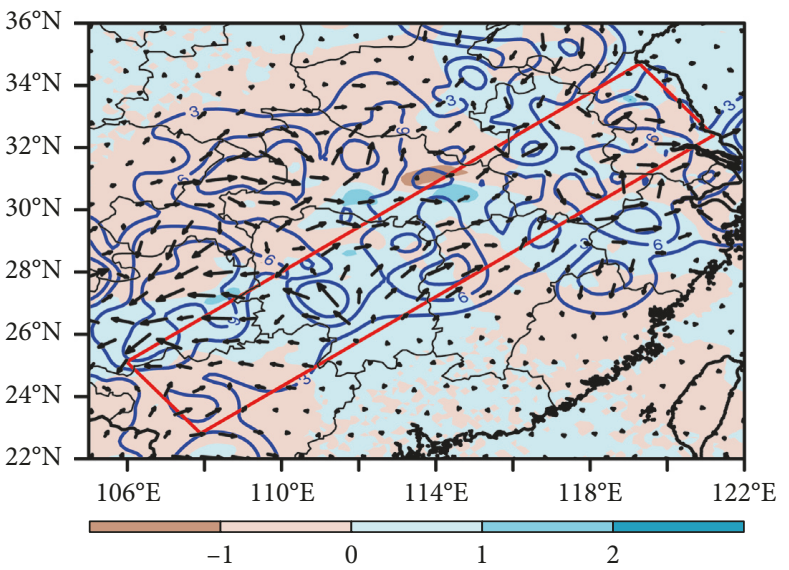

(d)

Figure 7: Wind (wind barbs) and relative humidity (shaded, unit: \%) at $700 \mathrm{hPa}$ and geopotential height (blue lines, unit: 10 gpm) at $500 \mathrm{hPa}$ ((a) CON, (b) RAD, (c) RADC) and wind increments between initial conditions for (d) RAD and CON (blue lines indicate wind velocity, unit: $\mathrm{m} / \mathrm{s}$ ) and specific humidity increment between RADC and RAD (shaded in (d), unit: g/kg) at $700 \mathrm{hPa}$.

the correction method to correct radar reflectivity. Since there are no hydrometers in the conventional observations and radar reflectivity is used to correct the cloud analysis, the analyzed hydrometeor increments are mainly concentrated in the area where radar echo increment occurs. The humidity analysis method developed by Birkenheuer [24] indirectly adjusts the humidity field using radar reflectivity. This incloud humidity correction is shown in Figure $8(\mathrm{~b})$ as positive humidity increases. It is mainly distributed below $850 \mathrm{hPa}$, and the maximum increment is more than $3.5 \mathrm{~g} / \mathrm{kg}$. The positive humidity disturbance may be beneficial for counteracting the negative buoyancy associated with the introduction of hydrometeors and evaporative cooling and for maintaining the development of rainstorm system. The positive increments of cloud water in the upper troposphere (Figure 8(c)) and cloud ice (Figure 8(d)), snow (Figure 8(e)), and rainwater in the lower troposphere (Figure $8(\mathrm{f})$ ) are mainly distributed over the key rainstorm area. The increment of the hydrometers in the lower troposphere is much larger than that in the upper layer. The increment of snow is the largest with a maximum value of more than $1.4 \mathrm{~g} / \mathrm{kg}$, followed by that of rainwater with a maximum value of about $0.7 \mathrm{~g} / \mathrm{kg}$. The increments of cloud water and cloud ice are the minimum, and their maximum increment is less than $0.1 \mathrm{~g} / \mathrm{kg}$. This may be due to the fact that the strong radar reflectivity at the middle and lower levels is greatly corrected by using the correction method, which subsequently affects the analysis of low-level hydrometers in LAPS cloud analysis.

3.3. Simulation of Physical Variables. In order to analyze in detail the forecast difference between the three experiments, observed and simulated radar echoes at different time and levels are plotted. Figure 9 shows radar echoes at the height of $3 \mathrm{~km}$ at 0300 UTC 4 July 2014. The horizontal resolution of the simulation experiments is $9 \mathrm{~km}$. This resolution probably is too coarse, and thus, small convection cells observed by radars are not simulated in the three experiments. However, the main convection cells can be reproduced. There are two main convective cells observed by radars. The one occurred in southeastern Hubei is named A, and the other occurred in southern central Anhui is named B (shown in Figure 9(a)). Compared with observations, the 


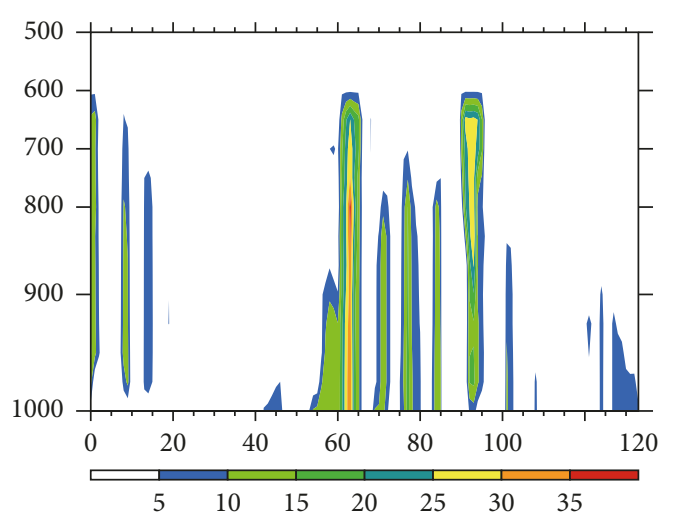

(a)

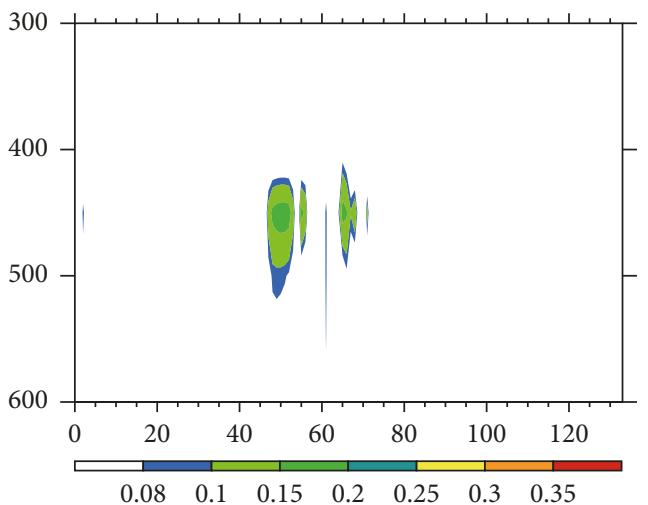

(c)

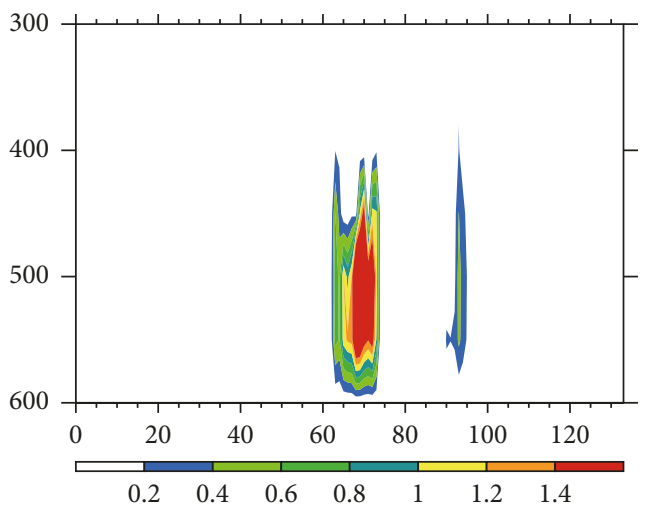

(e)

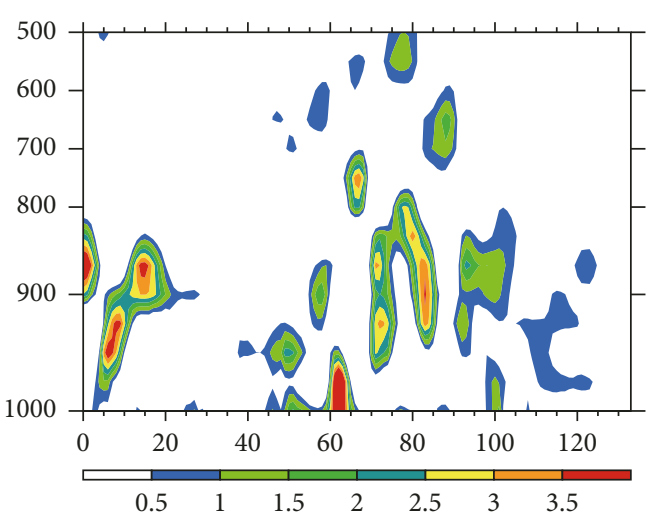

(b)

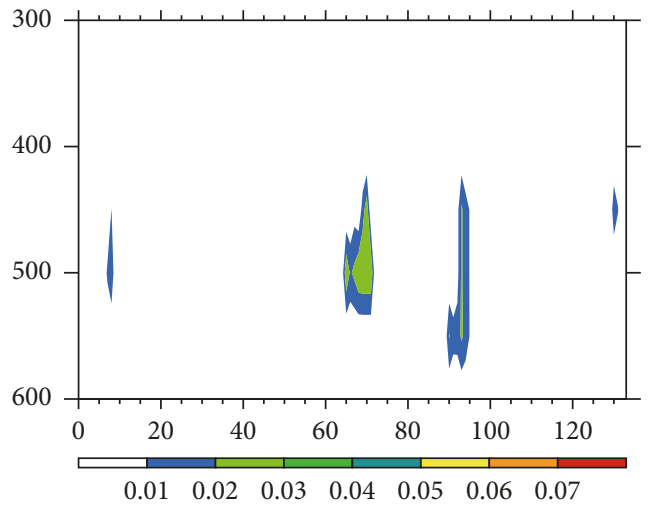

(d)

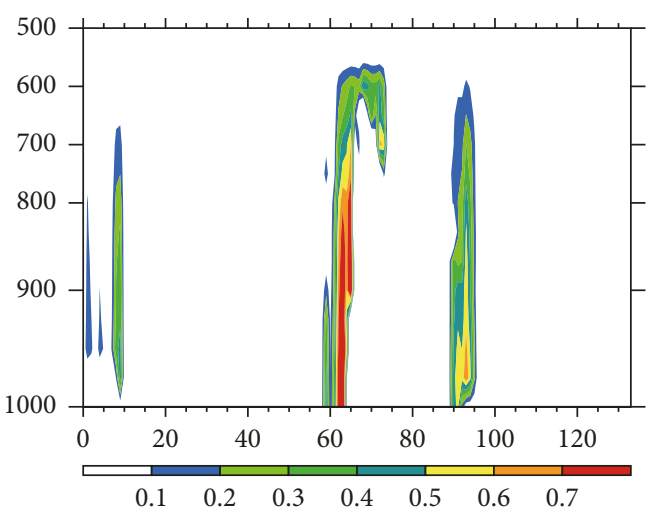

(f)

FIGURE 8: Cross sections of increments of radar echoes (a) (unit: dBZ), specific humidity (b) (unit: g/kg), and cloud hydrometeors ((c) cloud water, (d) cloud ice, (e) snow, and (f) rainwater, unit: g/kg) along line MN in Figure 3(a) at 0000 UTC 4 July 2014. The horizontal axis is the distance from line EF (Figure 3(a)) (unit: $10 \mathrm{~km}$ ). The vertical axis is pressure (unit: $\mathrm{hPa}$ ).

location of convective cell $\mathrm{A}$ is too far west and the range of convection cell B is smaller (Figure $9(\mathrm{~b})$ ) in the simulation of CON. The shapes, positions, and intensities of the convective cells simulated by RAD and RADC with assimilating radar data are closer to observations. The position and intensity of the convective cell A simulated by the two radar assimilation experiments are similar to observations, but its scale is smaller. The shape and position of the convective cell $\mathrm{B}$ simulated in RADC are better than that in RAD, and its position in RAD is far too west (Figures 9(c) and 9(d)). Similar situations can be found at other time. Therefore, we can conclude that the initial model conditions are improved with radar data assimilation, and the development and evolution of convective cells in this heavy rainfall event are better simulated with radar data assimilation. RADC with the correction method yields the best result.

To quantitatively evaluate the precipitation forecast, $1 \mathrm{~h}$ precipitation forecast threat score (TS) [37] is calculated. The threat score (TS) is simply the ratio of successful event forecasts to the total number of event forecasts. Consider a set of forecasts that can have only two alternatives (e.g., yes and no). TS is defined as 


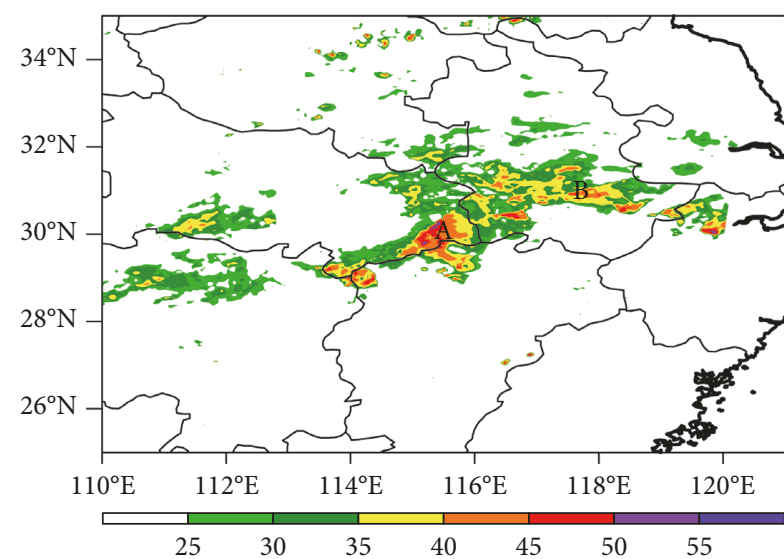

(a)

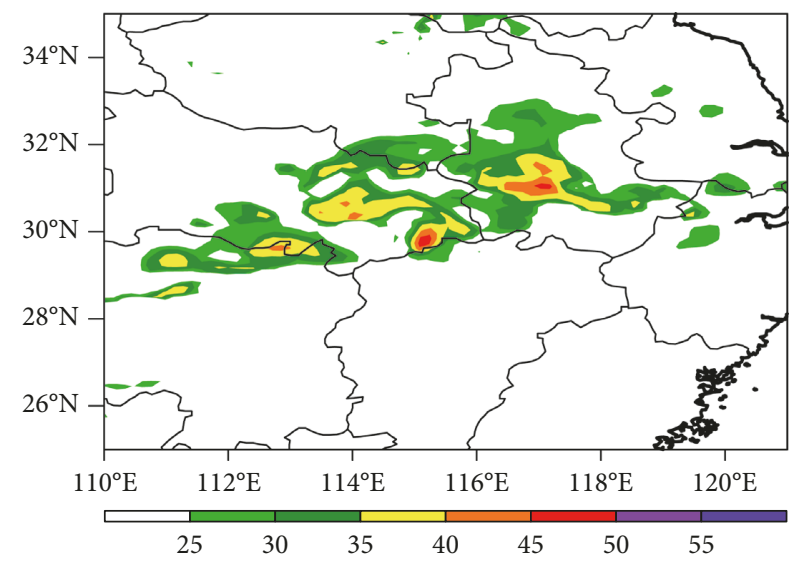

(c)

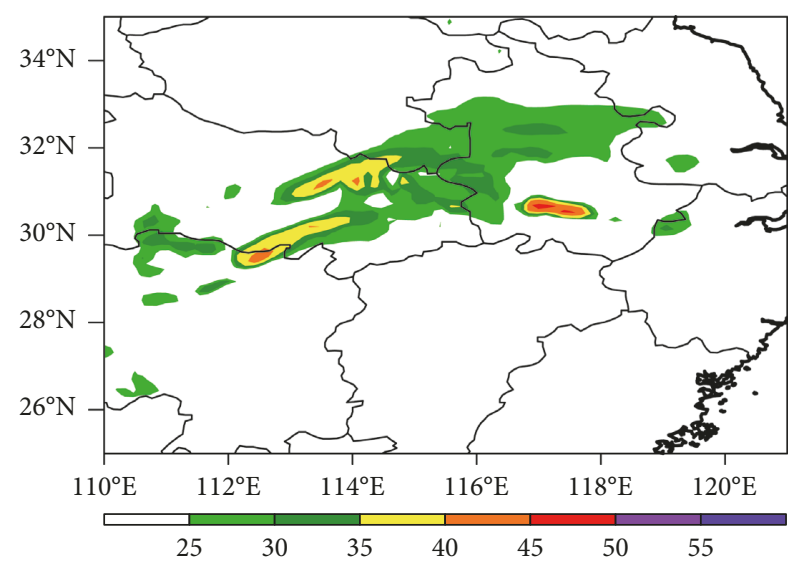

(b)

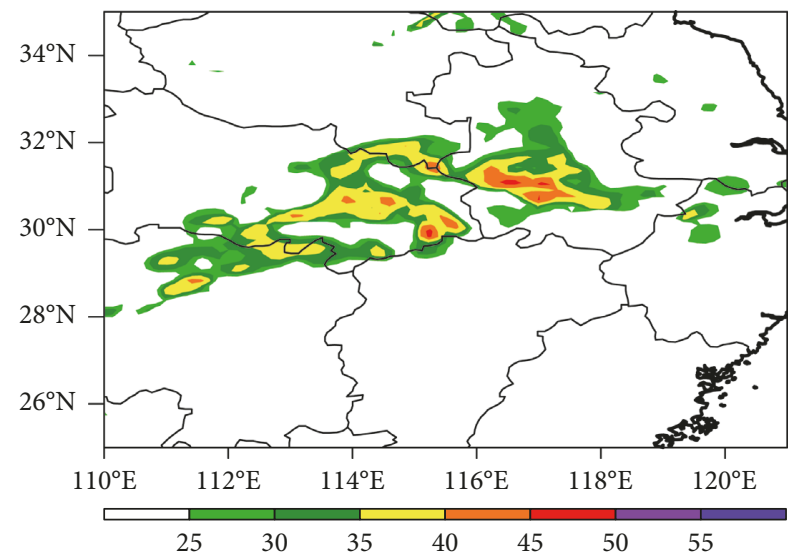

(d)

FIgURE 9: Radar echoes at the height of $3 \mathrm{~km}$ at 0300 UTC 4 July 2014: (a) observations, (b) CON, (c) RAD, and (d) RADC (unit: dBZ).

$$
\mathrm{TS}=\frac{X}{(X+Y+Z)},
$$

where $X$ denotes the number of positive (yes) forecasts that correspond to an occurrence of the event, $Y$ denotes the number of events that occurred in conjunction with a negative forecast, and $Z$ denotes the number of negative forecasts that did not have any associated events.

Figure 10 shows $1 \mathrm{~h}$ TS for $0.1 \mathrm{~mm}, 5 \mathrm{~mm}, 10 \mathrm{~mm}$, and $15 \mathrm{~mm}$ thresholds in the rainfall area (black box in Figure 3(a)). For the $1 \mathrm{~h}$ precipitation exceeding $0.1 \mathrm{~mm}$, the TSs of CON, RAD, and RADC are similar (Figure 10(a)), which suggests that the rainfall location and evolution with time simulated by the three experiments are similar. For the heavier rainfall (Figures 10(b)-10(d)), the $1 \mathrm{~h}$ TSs of RAD and RADC with assimilation of radar data are greater than that of CON; especially in the first eight hours, the scores of the two radar data assimilation experiments are far greater than that of CON. Eight hours later, the $1 \mathrm{~h}$ rainfall amount becomes larger and the $1 \mathrm{~h}$ TS is higher. The $1 \mathrm{~h}$ TS at most time is higher for RAD and RADC than for CON. Compared with RAD, the $1 \mathrm{~h}$ TS of RADC for heavier rainfall is higher than that of RAD. In summary, RADC with radar reflectivity correction has the best simulation result of rainfall during this event.
The intensity of updraft is an important factor of the rainstorm system. Figure 11 shows cross sections of vertical velocity and potential equivalent temperature $\left(\theta_{\mathrm{e}}\right)$ over the rainstorm area. Three hours later, the low values of $\theta_{\mathrm{e}}$ simulated in the experiments are located at the height of $3-6 \mathrm{~km}$ above the rainstorm area. Convective unstable stratification is found below $4 \mathrm{~km}$, and $\theta_{\mathrm{e}}$ decreases with increasing height. In CON, the ascending motion over the heavy rainfall area is weak and the maximum radar echo is only $30 \mathrm{dBZ}$ (Figure 11(a)). RAD and RADC with radar data assimilation create two convection cells with the scale of $10-20 \mathrm{~km}$. There exist strong updrafts within the convection cells. The ascending motion extends from the lower levels to the upper troposphere above $12 \mathrm{~km}$ (Figures 11(b) and 11(c)). Compared with that in RAD, the convective cells simulated in RADC are stronger and the maximum radar echo is over $45 \mathrm{dBZ}$. The simulated convection cells correspond to the locations of the two rainstorms at this time shown in Figure 5(a). This result indicates that, by assimilating radar reflectivity data, the convective cells in the heavy rainfall event can be well simulated. The structure of the rainstorm system simulated in RADC using the correction method is a little better than that in RAD. 


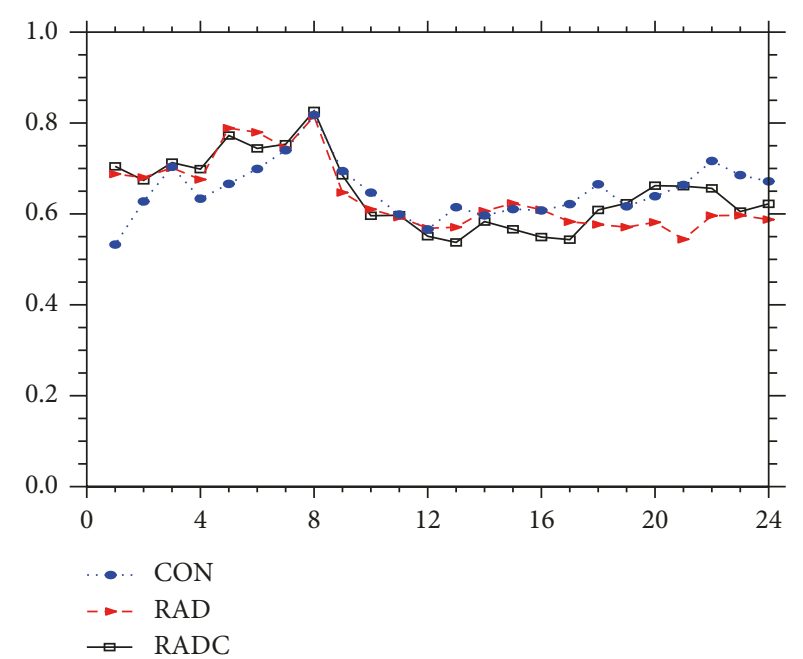

(a)

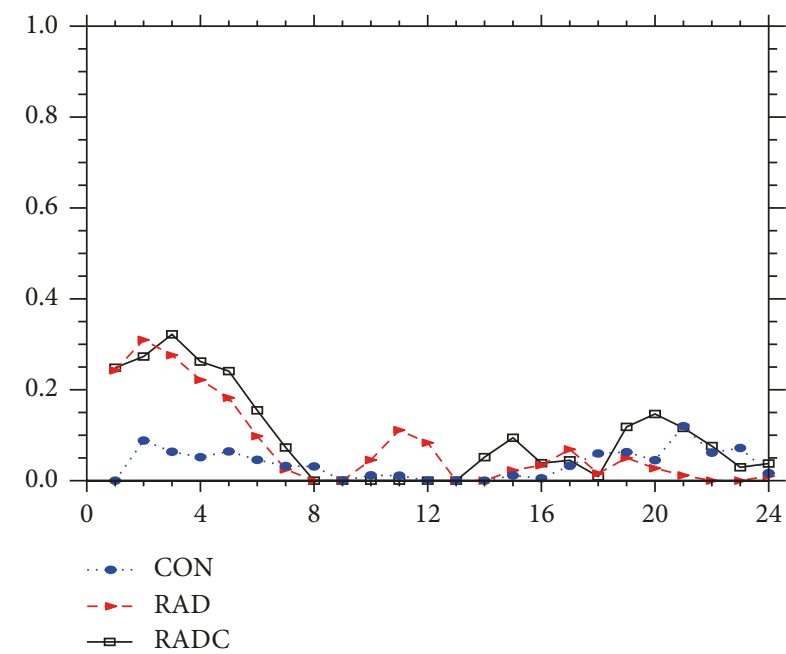

(c)

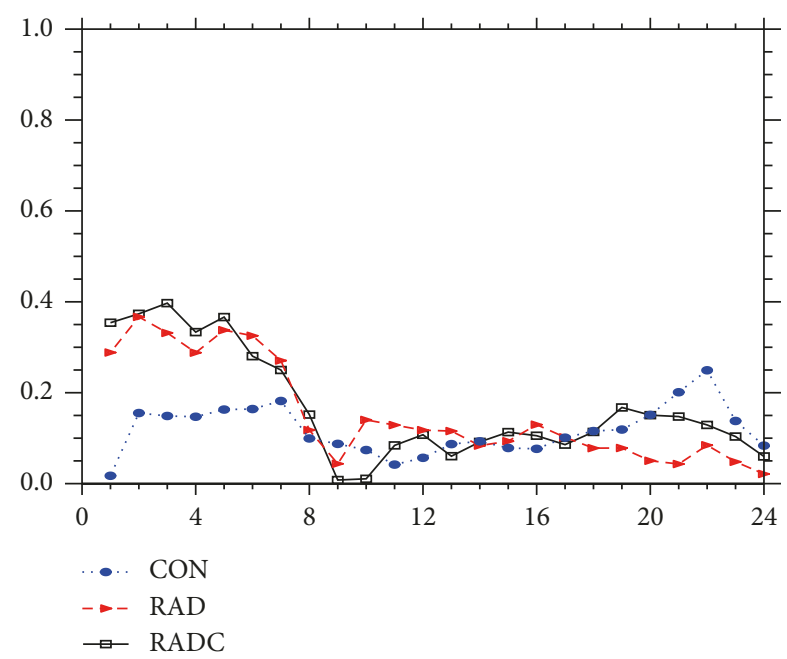

(b)

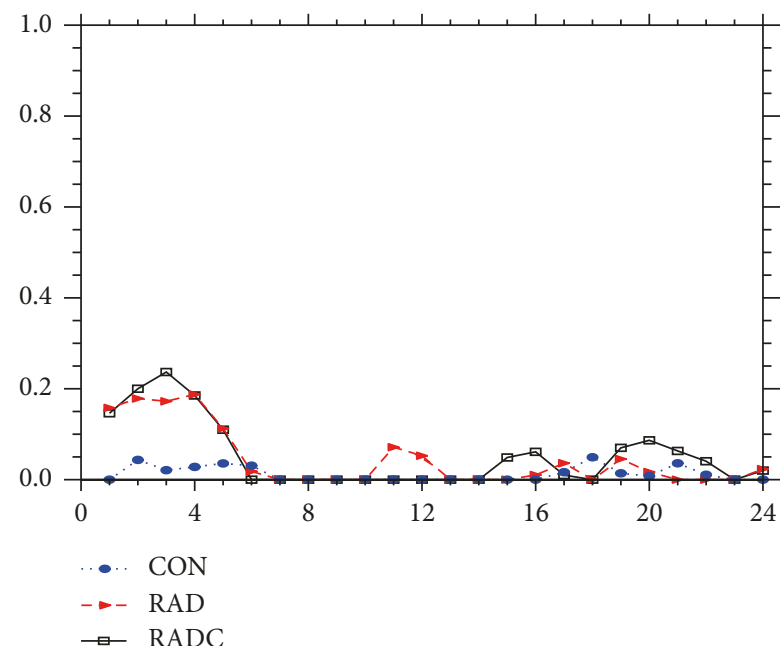

(d)

Figure 10: The $1 \mathrm{~h}$ TSs of CON, RAD, and RADC for various thresholds: (a) $\geq 0.1 \mathrm{~mm} / \mathrm{h}$, (b) $\geq 5 \mathrm{~mm} / \mathrm{h},(\mathrm{c}) \geq 10 \mathrm{~mm} / \mathrm{h}$, and (d) $15 \mathrm{~mm} / \mathrm{h}$. The horizontal axis is forecast hours from 0000 UTC 4 July to 0000 UTC 5 July 2014.

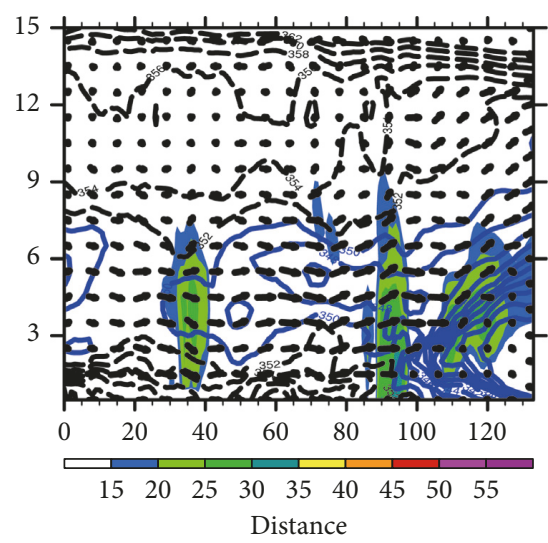

(a)

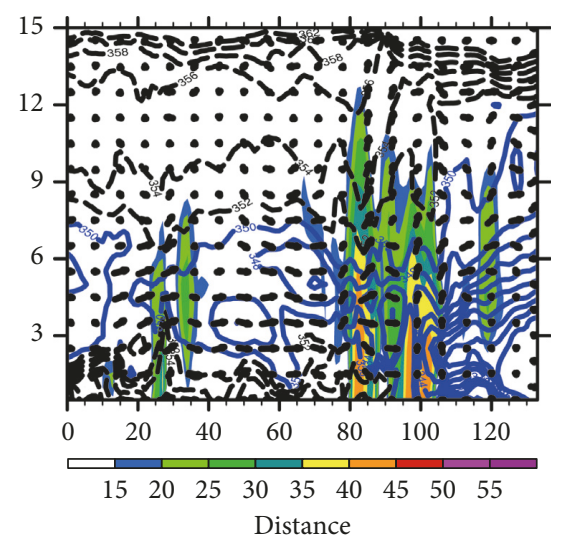

(b)

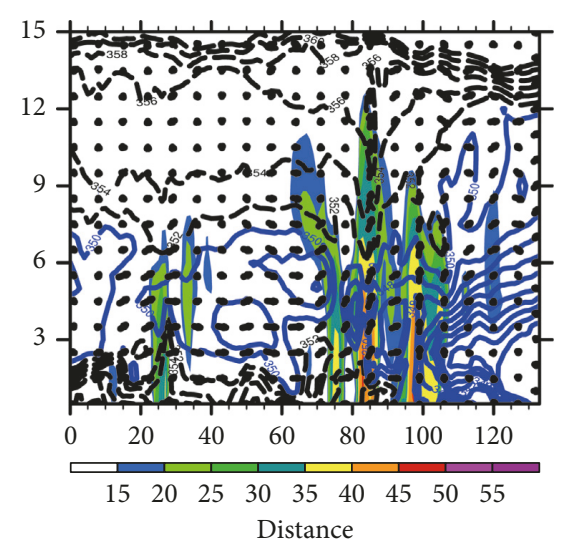

(c)

Figure 11: Cross sections of radar echoes (shaded, unit: dBZ), potential equivalent temperature $\theta_{\mathrm{e}}$ (unit: K; solid blue line: $\theta_{\mathrm{e}} \leq 350 \mathrm{~K}$; solid black line: $\theta_{\mathrm{e}} \leq 350 \mathrm{~K}$ ) and wind (vectors) ((a) CON, (b) RAD, and (c) RADC) along line MN in Figure 3(a) at 0300 UTC 4 July 2014 . The horizontal axis is the distance from line EF (Figure 3(a)) (unit: $10 \mathrm{~km}$ ). The vertical axis is height (unit: $\mathrm{m}$ ). 


\section{Summary and Conclusions}

A heavy Meiyu frontal rainfall event occurred in the Yangtze-Huaihe River Basin from 4 to 5 July 2014 is studied with observed radar data assimilation. A new correction method is developed to correct three-dimensional radar reflectivity data based on hourly surface rain gauge observations. Three numerical experiments are carried out using LAPS and WRF to evaluate the impact of radar data assimilation on the simulation of this heavy rainfall event, and the performance of the correction method is evaluated by assimilating radar reflectivity observations into LAPS.

The results show that the assimilation of radar data can effectively correct the location errors in the background and improve the simulation of the heavy rain. The heavy rainfall simulated with assimilation of radar data derived from hourly surface rain gauge observations is the closest to observations in terms of the location, intensity, and evolution of rainfall with time. The overestimation of rainfall in the other two experiments is successfully corrected due to the assimilation of radar data.

The southwesterly low-level jet stream in the rainstorm area is enhanced by assimilation of radial wind data, and the correction of radar reflectivity is helpful to increase the humidity over the rainstorm area. The initial background field adjusted by radar data assimilation provides a more realistic environmental condition for the development and maintenance of the rainstorm system. Radar echoes in the rainstorm area are enhanced by using the correction method, which corrects radar reflectivity. The analyzed hydrometeors and humidity increments are mainly concentrated in the area where radar echoes are increased. The positive humidity disturbance might be able to counteract the negative buoyancy associated with the introduction of hydrometers and evaporative cooling and thus is favorable for the maintenance and development of rainstorm system.

The convective cells in the heavy rainfall event can be well simulated with assimilation of radar reflectivity data, and the simulated structure of the rainstorm system by using the correction method is consistent with the evolution of observed rainfall.

Our conclusions here are mainly based on a single case study. Radar observations provide a promising source for better initialization in numerical studies of such kind of heavy rainfall events. More methods are needed to explore uncertain issues regarding how to better utilize radar observations and how to evaluate the impacts of radar data assimilation on numerical weather forecast. Our future work will focus on more case studies for the purpose to reach more reliable conclusions and further improve the ability of numerical models for the forecast of heavy Meiyu frontal rainfall in the Yangtze River Basin.

\section{Data Availability}

The data used to produce the results of this paper are available from Hongli Li (lihongli@whihr.com.cn) upon request.

\section{Conflicts of Interest}

The authors declare that they have no conflicts of interest.

\section{Acknowledgments}

This study was supported jointly by the Key Program for International S\&T Cooperation Projects of China (Grant no. 2016YFE0109400) and the National Natural Science Foundation of China (Grant nos. 41620104009 and 41105072).

\section{References}

[1] N. M. Truong, V. T. Hang, R. A. Pielke et al., "Synoptic-scale physical mechanisms associated with the Mei-yu front: a numerical case study in 1999," Asia-Pacific Journal of Atmospheric Sciences, vol. 48, no. 4, pp. 433-448, 2012.

[2] J. Zhu, D. Q. Huang, and T. Yang, "Changes of Meiyu system in the future under A1B scenario simulated by MIROC_Hires model," Theoretical and Applied Climatology, vol. 123, no. 3, pp. 461-471, 2016.

[3] Y. L. Luo and Y. R. X. Chen, "Investigation of the predictability and physical mechanisms of an extreme-rainfallproducing mesoscale convective system along the Meiyu front in east China: an ensemble approach," Journal of Geophysical Research-Atmospheres, vol. 120, no. 20, pp. 10593-10618, 2015.

[4] X. Y. Ma and Y. C. Zhang, "Numerical study of the impacts of urban expansion on Meiyu precipitation over Eastern China," Journal of Meteorological Research, vol. 29, no. 2, pp. 237-256, 2015.

[5] F. Ping, Z. X. Luo, X. B. Tang et al., "A simulation of the merger of convective clouds in the torrential rainfalls associated with the Meiyu front," Meteorology and Atmospheric Physics, vol. 123, no. 1, pp. 51-65, 2014.

[6] H. F. Shen, G. Q. Zhai, Y. Zhu et al., "Numerical study of a mesoscale vortex in the planetary boundary layer of the Meiyu front," Acta Meteorologica Sinica, vol. 26, no. 6, pp. 788-802, 2012.

[7] J. Z. Sun, "Convective-scale assimilation of radar data: progress and challenges," Quarterly Journal of the Royal Meteorological Society, vol. 131, no. 613, pp. 3436-3463, 2005.

[8] Q. Xiao and J. Sun, "Multiple-radar data assimilation and short-range quantitative precipitation forecasting of a squall line observed during IHOP_2002," Monthly Weather Review, vol. 135, no. 10, pp. 3381-3404, 2007.

[9] S. Sugimoto, N. A. Crook, J. Z. Sun et al., “An examination of WRF 3DVAR radar data assimilation on its capability in retrieving unobserved variables and forecasting precipitation through observing system simulation experiments," Monthly Weather Review, vol. 137, no. 11, pp. 4011-4029, 2009.

[10] J. D. Gao and D. J. Stensrud, "Assimilation of reflectivity data in a convective-scale, cycled 3DVAR framework with hydrometeor classification," Journal of the Atmosphere Sciences, vol. 69, no. 3, pp. 1054-1065, 2012.

[11] M. Hu, M. Xue, and K. Brewster, "3DVAR and cloud analysis with WSR-88D Level-II data for the prediction of the Fort Worth, Texas, tornadic thunderstorms. part I: cloud analysis and its impact," Monthly Weather Review, vol. 134, no. 2, pp. 675-689, 2006.

[12] J. D. Gao, M. Xue, K. Brewster, and K. K. Droegemeier, “A three dimensional variational data assimilation method with recursive filter for single-Doppler radar," Journal Atmospheric Oceanic Technology, vol. 21, no. 3, pp. 457-469, 2004.

[13] C. D. Jones and B. Macpherson, "A latent heat nudging scheme for the assimilation of precipitation data into an operational mesoscale model," Meteorological Applications, vol. 4, no. 3, pp. 269-277, 1997. 
[14] Q. N. Xiao, Y. H. Kuo, J. Z. Sun et al., "Assimilation of Doppler radar observations with a regional 3DVAR system: impact of Doppler velocities on forecasts of a heavy rainfall case," Journal of Applied Meteorology, vol. 44, no. 6, pp. 768-788, 2005.

[15] M. J. Tong and M. Xue, "Ensemble Kalman filter assimilation of Doppler radar data with a compressible nonhydrostatic model: OSS experiments," Monthly Weather Review, vol. 133, no. 7, pp. 1789-1807, 2005.

[16] D. C. Dowell, L. J. Wicker, and C. Snyder, "Ensemble Kalman filter assimilation of radar observations of the 8 May 2003 Oklahoma city supercell: influences of reflectivity observations on storm-scale analyses," Monthly Weather Review, vol. 139, no. 1, pp. 272-294, 2011.

[17] A. Aksoy, D. C. Dowell, and C. Snyder, "A multicase comparative assessment of the ensemble Kalman filter for assimilation of radar observations. Part I: storm-scale analyses," Monthly Weather Review, vol. 137, no. 6, pp. 1805-1824, 2009.

[18] P. Lopez and P. Bauer, "1D+4DVAR assimilation of NCEP stage-IV radar and gauge hourly precipitation data at ECMWF," Monthly Weather Review, vol. 135, no. 7, pp. 2506-2524, 2007.

[19] H. L. Wang, J. Z. Sun, S. Y. Fan et al., "Indirect assimilation of radar reflectivity with WRF $3 \mathrm{D}-\mathrm{Var}$ and its impact on prediction of four summer time convective events," Journal of Applied Meteorology and Climatology, vol. 52, no. 4, pp. 889-902, 2013.

[20] S. C. Albers, J. A. McGinley, D. L. Birkenheuer et al., "The local analysis and prediction system (LAPS): analyses of clouds, precipitation, and temperature," Weather Forecasting, vol. 11, no. 3, pp. 273-287, 1996.

[21] Y. F. Xie, S. C. Albers, H. L. Jiang et al., "Variational cloud analysis using CRTM in a multiscale analysis," in Proceedings of 93rd American Meteorological Society Annual Meeting, Austin, TX, USA, June 2013.

[22] H. L. Li and X. D. Xu, "Application of a three-dimensional variational method for radar reflectivity data correction in a mudslide-inducing rainstorm simulation," Advance in Atmospheric Sciences, vol. 34, no. 4, pp. 469-481, 2017.

[23] J. A. McGinley, S. C. Albers, and P. A. Stamus, "Validation of a composite convective index as defined by a real-time local analysis system," Weather Forecasting, vol. 6, no. 3, pp. 337-356, 1991.

[24] D. Birkenheuer, "The effect of using digital satellite imagery in the LAPS moisture analysis," Weather Forecasting, vol. 14, no. 5, pp. 782-788, 1999.

[25] S. C. Albers, "The LAPS wind analysis," Weather and Forecasting, vol. 10, no. 2, pp. 342-352, 1995.

[26] C. A. Hiemstra, G. E. Liston, R. A. Pielke, D. L. Birkenheuer, and S. C. Albers, "Comparing local analysis and prediction system (LAPS) assimilations with independent observations," Weather and Forecasting, vol. 21, no. 6, pp. 1024-1040, 2006.

[27] D. Conte, M. M. Miglietta, and V. Levizzani, "Analysis of instability indexes during the development of a Mediterranean tropical-like cyclone using MSG-SEVIRI products and the LAPS model," Atmospheric Research, vol. 101, no. 1-2, pp. 264-279, 2011.

[28] A. Tiesi, M. M. Miglietta, D. Conte et al., "Heavy rain forecasting by model initialization with LAPS: a case study," IEEE Journal of Selected Topics in Applied Earth Observations and Remote Sensing, vol. 9, no. 6, pp. 2619-2627, 2016.

[29] J. Barcons, A. Folch, A. S. Afif, and J. R. Miro, "Assimilation of surface AWS using 3DVAR and LAPS an their effects on short-term high-resolution weather forecasts," Atmospheric Research, vol. 156, pp. 160-173, 2015.

[30] H. L. Li, B. Zhang, and B. Chen, "Local analysis and prediction system (LAPS) and its localization," Meteorological Science and Technology, vol. 36, no. 1, pp. 20-24, 2008, in Chinese.

[31] H. L. Li, C. G. Cui, and Z. B. Wang, "A study on application of Doppler radar data in LAPS," Plateau Meteorology, vol. 28, no. 1, pp. 1-107, 2009, in Chinese.

[32] H. L. Li, R. Wan, and Y. C. Xie, "Application of ground-based GPS water vapor in LAPS," Journal of Tropical Meteorology, vol. 26, no. 6, pp. 702-709, 2010, in Chinese.

[33] H. L. Li, J. X. Peng, and Y. X. Zhang, "Analysis on the role of various observation data in LAPS mesoscale analysis fields," Torrential Rain and Disasters, vol. 33, no. 3, pp. 273-284, 2014, in Chinese.

[34] S. Hu, S. Gu, X. Zhang, and H. Luo, "Automatic identification of storm cells using Doppler radars," Acta Meteorologica Sinica, vol. 21, pp. 353-365, 2007.

[35] Y. J. Xiao, "Three-dimensional multiple-radar reflectivity mosaics and its application study," Ph.D. thesis, Nanjing University of Information Science and Technology, Nanjing, China, 2007, in Chinese.

[36] Y. J. Xiao, Y. Wan, J. Wang, B. Wang, and Z. Wang, "Study of an automated Doppler radar velocity dealiasing algorithm," Plateau Meteorology, vol. 31, pp. 1119-1128, 2012, in Chinese.

[37] J. T. Schaefer, "The critical success index as an indicator of warning skill," Weather Forecasting, vol. 5, no. 4, pp. 570-575, 1990. 

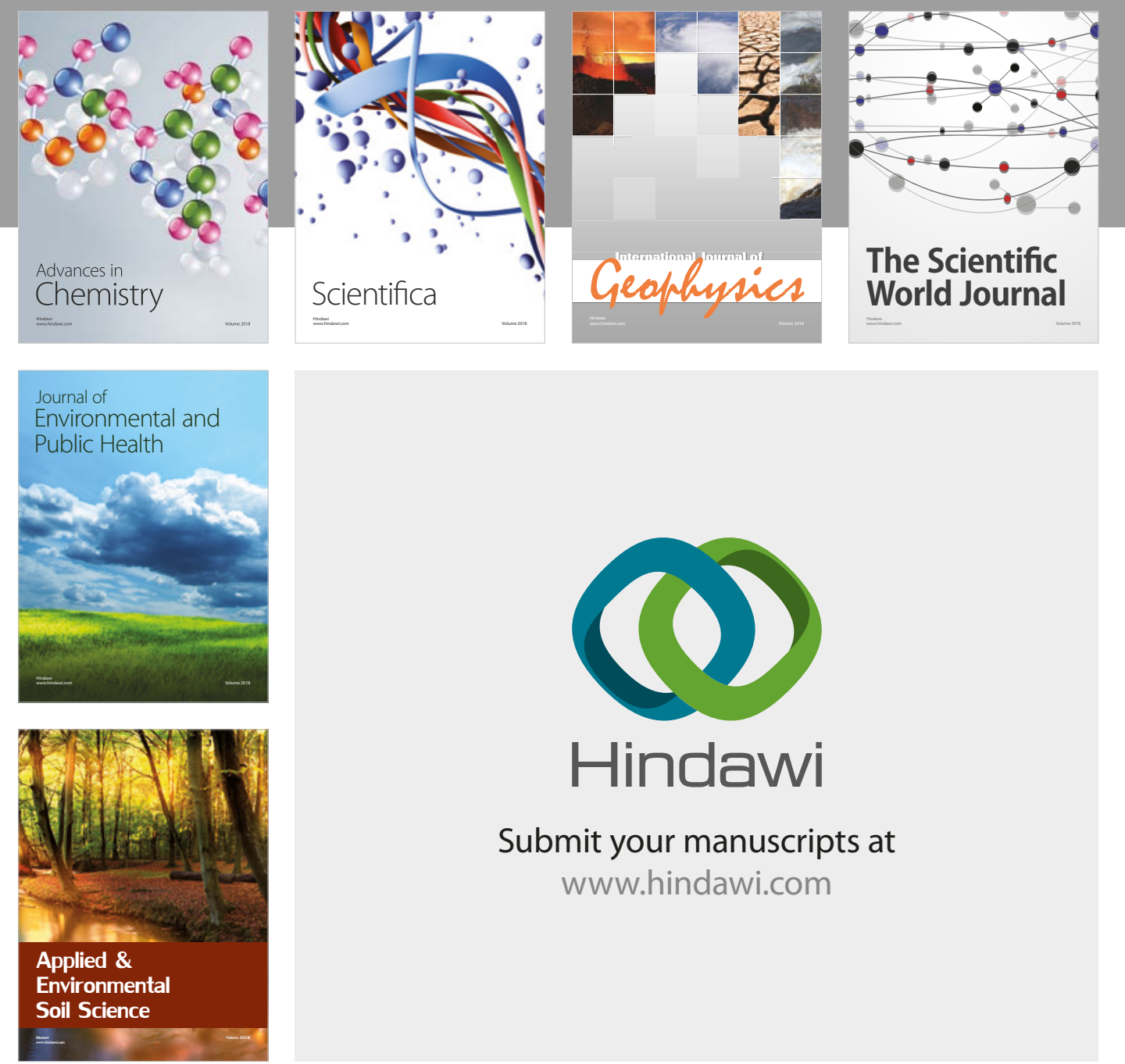

The Scientific

\section{World Journal}
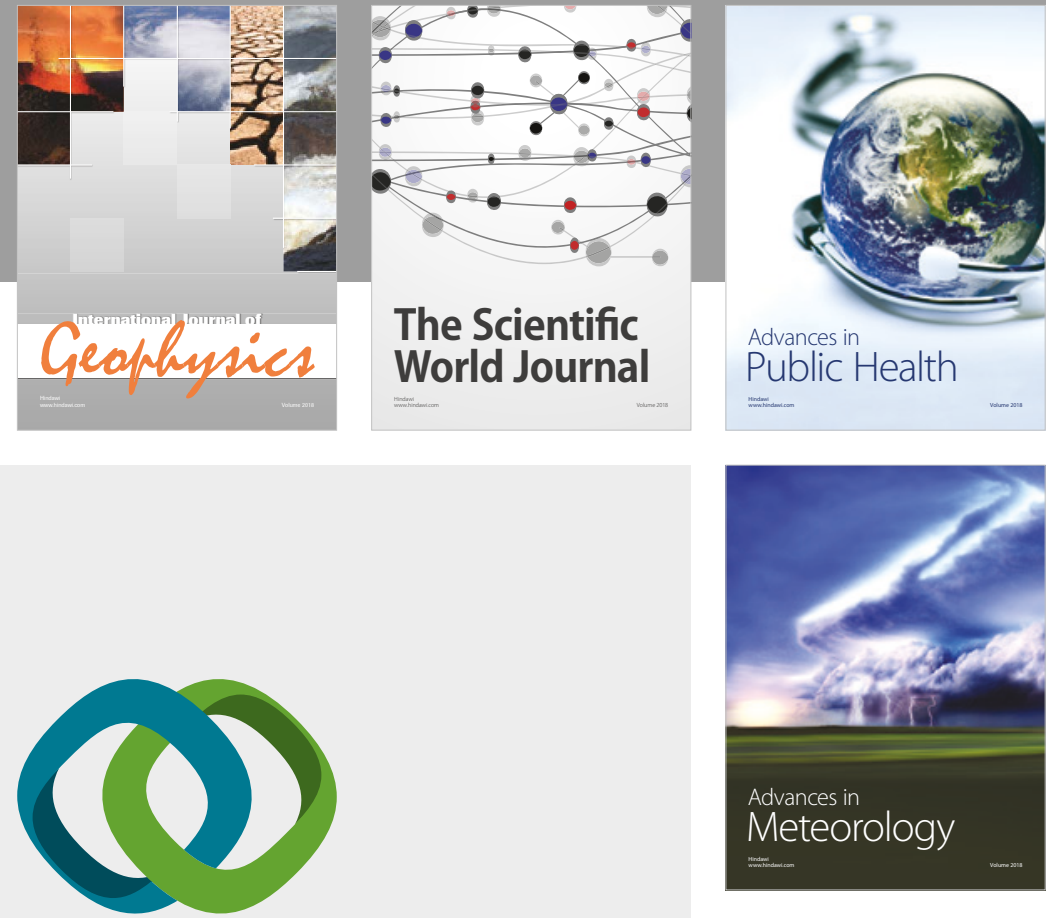

Advan

Public Health

\section{Hindawi}

Submit your manuscripts at

www.hindawi.com
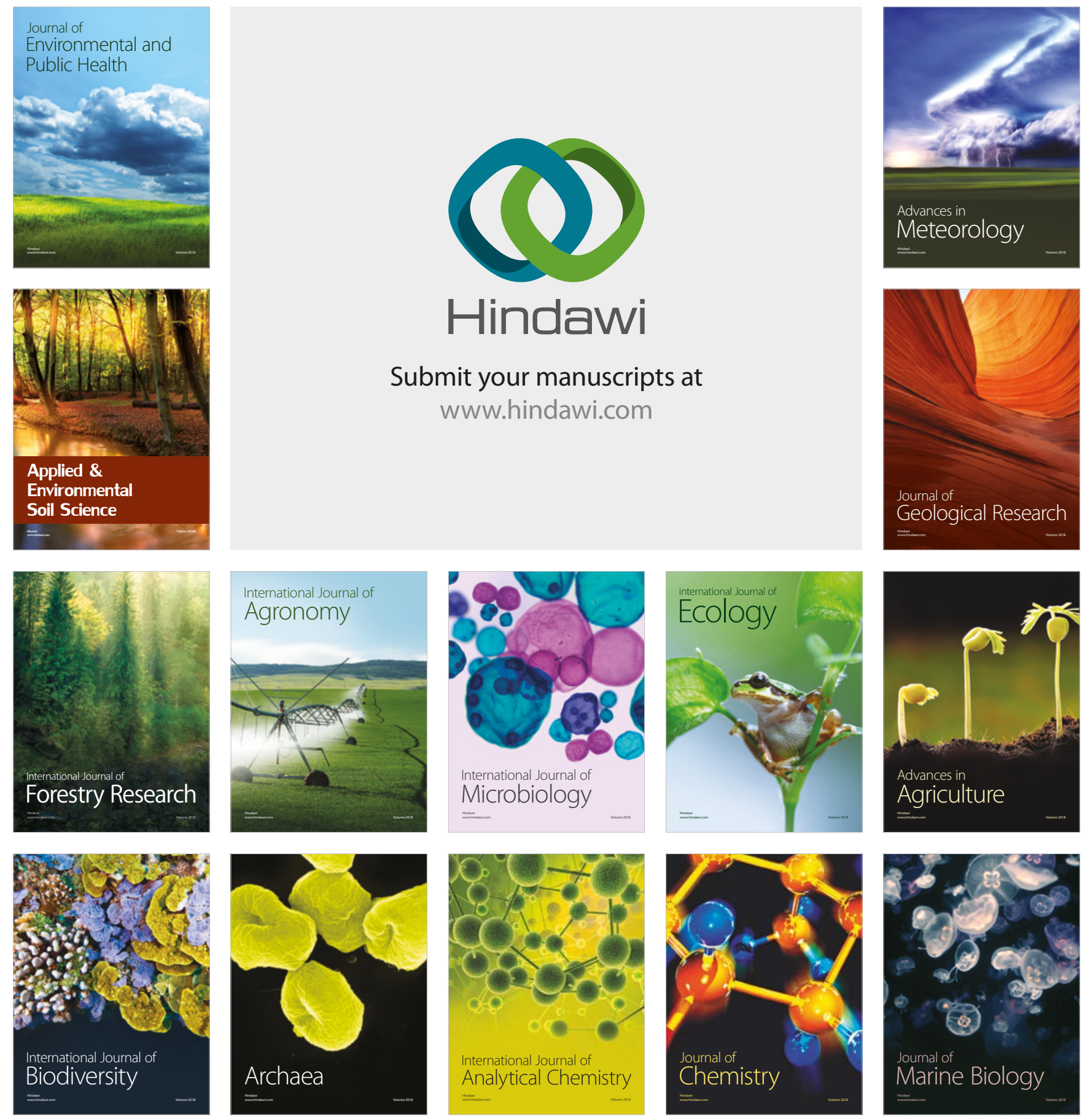